\title{
Signal Intensity of Stem Diameter Variation for the Diagnosis of Drip Irrigation Water Deficit in Grapevine
}

\author{
Chen Ru, Xiaotao Hu *, Wene Wang, Hui Ran, Tianyuan Song and Yinyin Guo
}

check for updates

Citation: Ru, C.; Hu, X.; Wang, W.; Ran, H.; Song, T.; Guo, Y. Signal Intensity of Stem Diameter Variation for the Diagnosis of Drip Irrigation Water Deficit in Grapevine.

Horticulturae 2021, 7, 154. https:// doi.org/10.3390/horticulturae7060154

Academic Editors:

Agnieszka Hanaka,

Jolanta Jaroszuk-Ściseł and

Małgorzata Majewska

Received: 16 May 2021

Accepted: 9 June 2021

Published: 15 June 2021

Publisher's Note: MDPI stays neutral with regard to jurisdictional claims in published maps and institutional affiliations.

Copyright: (c) 2021 by the authors. Licensee MDPI, Basel, Switzerland. This article is an open access article distributed under the terms and conditions of the Creative Commons Attribution (CC BY) license (https:// creativecommons.org/licenses/by/ $4.0 /)$.
Key Laboratory of Agricultural Soil and Water Engineering in Arid and Semiarid Areas, Ministry of Education, Northwest A\&F University, Yangling 712100, China; chenru1024@nwafu.edu.cn (C.R.); wangwene@nwsuaf.edu.cn (W.W.); huiran@nwsuaf.edu.cn (H.R.); tianyuansong1014@nwafu.edu.cn (T.S.); guoyinyin0513@nwafu.edu.cn (Y.G.)

* Correspondence: huxiaotao11@nwsuaf.edu.cn; Tel.: +86-138-9281-6133; Fax: +86-29-8708-2117

\begin{abstract}
Precise irrigation management of grapevines in greenhouses requires a reliable method to easily quantify and monitor the grapevine water status to enable effective manipulation of the water stress of the plants. This study describes a study on stem diameter variations of grapevine planted in a greenhouse in the semi-arid area of Northwest China. In order to determine the applicability of signal intensity of stem diameter variation to evaluate the water status of grapevine and soil. The results showed that the relative variation curve of the grapevine stem diameter from the vegetative stage to the fruit expansion stage showed an overall increasing trend. The correlations of MDS (maximum daily shrinkage) and DI (daily increase) with meteorological factors were significant $(p<0.05)$, and the correlations with SWP, RWC and soil moisture were weak. Although MDS and DI can diagnose grapevine water status in time, $\mathrm{SI}_{\mathrm{MDS}}$ and $\mathrm{SI}_{\mathrm{DI}}$ have the advantages of sensitivity and signal intensity compared with other indicators. Compared with MDS and DI, the $\mathrm{R}^{2}$ values of the regression equations of $\mathrm{SI}_{\mathrm{MDS}}$ and $\mathrm{SI}_{\mathrm{DI}}$ with SWP and RWC were high, and the correlation reached a very significant level $(p<0.01)$. Thus, $\mathrm{SI}_{\mathrm{MDS}}$ and $\mathrm{SI}_{\mathrm{DI}}$ are more suitable for the diagnosis of grapevine water status. The $\mathrm{SI}_{\mathrm{MDS}}$ peaked at the fruit expansion stage, reaching $0.957-1.384$. The signal-to-noise ratio of $\mathrm{SI}_{\mathrm{DI}}$ was higher than that of MDS across the three treatments at the vegetative stage. The value and signal-to-noise ratio of $\mathrm{SI}_{\mathrm{DI}}$ at the flowering stage were similar to those of $\mathrm{SI}_{\mathrm{MDS}}$, while the correlation between $\mathrm{SI}_{\mathrm{DI}}$ and the soil moisture content was higher than that of $\mathrm{SI}_{\mathrm{MDS}}$. It can be concluded that that $\mathrm{SI}_{\mathrm{DI}}$ is suitable as an indicator of water status of grapevine and soil during the vegetative and flowering stages. In addition, the signal-to-noise ratio of $\mathrm{SI}_{\mathrm{MDS}}$ during the fruit expansion and mature stages was significantly higher than that of $\mathrm{SI}_{\mathrm{DI}}$. Therefore, $\mathrm{SI}_{\mathrm{MDS}}$ is suitable as an indicator of the moisture status of grapevine and soil during the fruit expansion and mature stages. In general, $\mathrm{SI}_{\mathrm{MDS}}$ and $\mathrm{SI}_{\mathrm{DI}}$ were very good predictors of the plant water status during the growth stage and their continuous recording offers the promising possibility of their use in automatic irrigation scheduling in grapevine.
\end{abstract}

Keywords: grapevine; maximum daily shrinkage; daily increase; stem water potential; leaf relative water content; signal intensity

\section{Introduction}

Fruit tree orchards are common in arid and semi-arid areas where water for irrigation is scarce. This, together with an increasing world population that has to be fed and with other water-using sectors competing for the limited water resources, makes the use of precise irrigation techniques in those orchards unavoidable. The response of the scientific community to this challenge has been to invest a substantial amount of research in the development of deficit irrigation approaches [1,2] and of new irrigation technologies based on more-precise, user-friendly water-stress indicators. Some can be continuously and automatically recorded, having a great potential for irrigation scheduling [3]. 
In recent years, it has become very popular to study the relationship between plant and water based plant water status indicators [4]. There are many ways to monitor and diagnose crop water status. From the perspective of plant physiology, the short-term microchange dynamics of plant organs (stems, leaves, fruits, etc.) are closely related to the water status of plants and have been widely focused on by many scholars [2-4]. The most widely used approach for evaluating plant water status has been to determine leaf [5,6], stem water potential [6] and leaf water content [7-10]. Plant water potential is a significant and reliable indicator of plant water status for scheduling the irrigation of plants. Argyrokastritis et al. [5] established the relationship between leaf water potential and water stress index, which can well characterize the water deficit status of plants. Wang et al. [6] used leaf and stem water potential to characterize the water status of grapevine, which can well judge whether the grapevine is in deficit state and determine when to need irrigation. However, the main disadvantage of plant water potential is the relatively cumbersome measurement procedure, including the necessity of frequent trips to the field and a considerable input of labor. The robustness of the sensors used to measure stem diameter fluctuations have renewed interest in using these parameters as plant water status indicators $[1,6,11,12]$. Apart from being capable of an early detection of water stress, even if this is mild, these techniques permit continuous and automated recordings of the plant water status and an immediate, consistent and reliable response to water deficit [13-15].

Monitoring crop moisture conditions using the stem diameter microchange method has been popular since the mid-1980s. The microchange of plant stem diameter is closely related to its water status, when the root system absorbs enough water, the stem expands gradually, and when the water is deficient, the stem shrinks gradually. Therefore, it is possible to diagnose the water status of the plant with the microchange of stem diameter, which can provide an index for the real-time prediction of crop water shortage and precision irrigation [12,16,17]. Today, in fact, fruit tree orchards and vineyards are being irrigated based on changes in the stem diameter [18,19]. Among them, MDS and DI indexes are commonly studied today as the indicators of plant water content [20-22]. According to some previous studies, the ability of an index to be suitable for use as a water diagnosis indicator was mainly evaluated in terms of three qualities: sensitivity, signal intensity and variability. An appropriate indicator should have better sensitivity and signal intensity to water stress and exhibit less variability $[4,14,23]$. However, the disadvantage of this method is that it cannot determine whether the critical value is independent of crop species or growth stage. In addition, meteorological factors have a great influence on MDS under the same water conditions [24]. The maximum stem diameter over time can be used to diagnose water deficit, but the growth rate of the crop is different at different growth stages. Under high evaporation intensity at the mature stage, crop stems may also shrink even if the crop does not lack water, and the variation in daily MXSD (maximum stem diameter) has no more significance [25]. Therefore, it may be difficult to apply the MDS of stem diameter as a crop moisture stress signal in practice.

The observation of stem diameter and its dynamic changes is beneficial to the study of plant moisture changes under interlaced internal and external factors. However, the observation of stem diameter is easily influenced by meteorological factors [26-28]. How to eliminate the interference of external environmental factors on the variation in stem diameter is always the difficulty in determining the most appropriate indicator. Due to the influence of other factors, it was difficult to diagnose plant water content. Only the observed values of stem diameter variation and the prediction values of stem diameter variation under no water stress, should be calculated to assist in the diagnosis. The comparison of MDS and DI with reference factors (relative values) can be used to directly reflect crop water status. The signal intensity is obtained by standardizing the reference value of the stem diameter indicator under fully irrigated conditions and the measured value of actual growth conditions, which can effectively eliminate the influence of meteorological factors [29]. Thus, the accuracy of these equations is very important to future studies, as these equations are the foundation for diagnosing plant water content and making irrigation schemes based 
on plant stem diameter variations. Currently, existent studies concentrate mostly on the grapevine stem diameter variations in outdoor conditions and seldom did it to grapevines planted in a greenhouse $[22,30,31]$. In addition, the past research on the variation in stem diameter has mainly focused on the feasibility of moisture diagnosis, maximum daily shrinkage, daily increase, and other stem diameter indicators, which have been verified for use in the moisture status diagnosis of different crops [11,24,32-34]. The variation in stem diameter is influenced by environmental factors and the crop growth characteristics. The difference in crop growth at different growth stages may significantly affect the potential of stem diameter variation indicators for use in determining irrigation regimes. Therefore, different indicators should be applied in different growth stages [26]. There have been few reports on this topic, and further research is needed.

For these reasons above mentioned, this research selected the greenhouse grapevine as the study object. Because of its rich nutrition and delicious taste, grapevine has become a kind of world major fruit. In China, grapevines have been widely cultivated as well, and a considerable part among them are planted in sunlight greenhouses. Due to the present water shortage in the Northwest China, it is important to acquire accurate crop water content information and timely plan water-saving irrigation schemes, which benefit the sustainable development of local agriculture. Thus, the main aims of this study were as follows: (1) to explore the relative variation in the changes in MDS and DI in stem diameter during different stages; (2) to clarify the correlation of microchanges in stem diameter with stem water potential, leaf relative water content, and soil water content; (3) to evaluate whether $\mathrm{SI}_{\mathrm{MDS}}$ and $\mathrm{SI}_{\mathrm{DI}}$ can be applied to diagnose grapevine moisture and soil moisture status; (4) to analyze the sensitivity of signal intensity indicators and to determine the suitability of $\mathrm{SI}_{\mathrm{MDS}}$ and $\mathrm{SI}_{\mathrm{DI}}$ under different stages.

\section{Materials and Methods}

\subsection{Study Area}

The experiment was carried out in greenhouse of Yuhe Farm, Shaanxi Province, from March to July $2018\left(108.58^{\circ} \mathrm{E}, 37.49^{\circ} \mathrm{N}\right)$. The annual average rainfall in this area is $365.7 \mathrm{~mm}$, the annual average temperature is $8.3^{\circ} \mathrm{C}$, the annual relative humidity is $69.37 \%$, and the annual average duration of sunshine is $2893.5 \mathrm{~h}$, which is representative of the typical continental marginal monsoon climate of the area. Table 1 shows the meteorological data (cultivation stage averages) recorded over the experimental year. The test soil was an aeolian sandy soil. The chemical properties of the soil were as follows: the soil ammonium nitrogen was $7.48 \mathrm{mg} \cdot \mathrm{kg}^{-1}$, the nitrate nitrogen was $22.91 \mathrm{mg} \cdot \mathrm{kg}^{-1}$, the available phosphorus was $4.07 \mathrm{mg} \cdot \mathrm{kg}^{-1}$, and the available potassium was $163.47 \mathrm{mg} \cdot \mathrm{kg}^{-1}$. The physical properties of the soil are shown in Table 2.

\subsection{Experimental Design}

Six-year-old grapevine (early-maturing variety $6-12$, which was selected from the scarlet bud transformation in 1998) were planted in greenhouse, and grapevines with good growth and similar shapes were selected for the experiments. The entire growth period of grapevines can be divided into four main growth stages: the vegetative stage, the flowering stage, the fruit expansion stage, and the coloring mature stage, the cultivation period was 121 days during the growth season. The greenhouse was oriented east-west and was $70 \mathrm{~m}$ long and $9 \mathrm{~m}$ wide. The grapevine row width and row spacing were $0.8 \mathrm{~m}$ and $1.5 \mathrm{~m}$, respectively, and the plant spacing was $0.6 \mathrm{~m}$, with 14 grapevines per row. Artificial warming was carried out in greenhouse to ensure the growth temperature of grapevines on 11 March 2018. Drip irrigation was used in the experiment. A single-wing labyrinth drip irrigation belt (produced by Xinjiang Dayu Water Saving Company, Xinjiang, China) was adopted. The inner diameter and wall thickness of drip irrigation belt was $0.02 \mathrm{~m}$ and $0.018 \mathrm{~m}$, respectively. the distance between the drippers was $0.3 \mathrm{~m}$, the design flow of the dripper was $4.0 \mathrm{~L} \cdot \mathrm{h}^{-1}$, and the laying mode of the drip belt was one row of two pipes. 
Table 1. Meteorological data of different cultivation stages in greenhouse.

\begin{tabular}{ccccc}
\hline Cultivation Stage & $\mathbf{T}_{\mathbf{a}}$ & $\mathbf{R}_{\mathbf{a}}$ & $\mathbf{R H}$ & $\mathbf{V P D}$ \\
\hline vegetative stage & 18.8 & 301.0 & 53.8 & 0.33 \\
flowering stage & 19.7 & 327.9 & 50.4 & 0.35 \\
fruit expansion stage & 22.3 & 421.1 & 51.2 & 0.34 \\
coloring mature stage & 25.1 & 362.3 & 55.7 & 0.32 \\
\hline
\end{tabular}

Note: $\mathrm{T}_{\mathrm{a}}\left({ }^{\circ} \mathrm{C}\right)$ : air temperature; $\mathrm{R}_{\mathrm{a}}\left(\mathrm{w} \cdot \mathrm{m}^{-2}\right)$ : solar radiation; $\mathrm{RH}(\%)$ : relative humidity; $\mathrm{VPD}(\mathrm{kpa})$ : vapor pressure deficit.

Table 2. Physical properties of the soil.

\begin{tabular}{|c|c|c|c|c|c|c|c|}
\hline \multirow[b]{2}{*}{ Depth (cm) } & \multicolumn{4}{|c|}{ Textural Analysis } & \multirow[b]{2}{*}{$\begin{array}{c}\text { FC } \\
\left(g \cdot g^{-1}\right)\end{array}$} & \multirow{2}{*}{$\begin{array}{c}\text { PWP } \\
\left(\mathrm{g} \cdot \mathrm{g}^{-1}\right)\end{array}$} & \multirow{2}{*}{$\begin{array}{c}\text { Bulk } \\
\text { Density } \\
\left(\mathrm{g} \cdot \mathrm{cm}^{-3}\right)\end{array}$} \\
\hline & Sand $(\%)$ & Clay (\%) & Silt (\%) & $\begin{array}{l}\text { Texture } \\
\text { Class }\end{array}$ & & & \\
\hline $0-40$ & 87.54 & 5.27 & 7.19 & Aeolian soil & 13.18 & 2.31 & 1.64 \\
\hline $40-80$ & 70.23 & 19.53 & 10.24 & Sandy loam & 17.45 & 6.38 & 1.46 \\
\hline
\end{tabular}

Note: FC: field capacity; PWP: permanently wilting point.

The experiment was conducted with drip-irrigated grapevines under three irrigation treatments: a full irrigation treatment $\left(\mathrm{T}_{1}: 100 \% \mathrm{M}\right)$ and two regulated deficit irrigation treatment $\left(\mathrm{T}_{2}: 80 \% \mathrm{M} ; \mathrm{T}_{3}: 60 \% \mathrm{M}\right), \mathrm{M}$ represents the irrigation quota. There were three treatments in total and three plots per treatment (each plot had a length of $8 \mathrm{~m}$, a width of $4.5 \mathrm{~m}$, and an area of $36 \mathrm{~m}^{2}$ ), with a random block arrangement. The irrigation dates and irrigation amount is shown in Table 3, the grapevines were irrigated 12 times during the entire growth period. The irrigation quota was calculated by Equation (1). The irrigation time was determined according to whether or not $\mathrm{T}_{1}$ reached the lower limit of the water quantity, which was $65 \%$ of $\beta_{1}$ at the vegetative and coloring mature stages and $70 \%$ of $\beta_{1}$ at the flowering and fruit expansion stage. The predicted wet layer depth of the soil was $0.8 \mathrm{~m}$. The total amount of fertilization during the entire growth period was $0.84 \mathrm{t} \cdot \mathrm{ha}^{-1}$, and the proportion of N:P:K was 1.0:0.6:1.2. Fertilization was carried out over three periods: the germination stage accounted for $20 \%$ of the total amount of fertilization, the flowering and fruit expansion stages accounted for $60 \%$, and the coloring mature stage accounted for $20 \%$. The drip irrigation and fertilization were controlled by integrated irrigation and fertilization equipment.

$$
M=0.1 \gamma_{s} H P\left(\beta_{1}-\beta_{2}\right)
$$

where $M$ represents the irrigation quota, $\mathrm{mm} ; \gamma_{s}$ represents the soil dry bulk density, $1.64 \mathrm{~g} \cdot \mathrm{cm}^{-3}$ in $0-40 \mathrm{~cm}$ soil depth, $1.46 \mathrm{~g} \cdot \mathrm{cm}^{-3}$ in $40-80 \mathrm{~cm}$ soil depth; $H$ is the predicted wet layer depth of soil, $0.8 \mathrm{~m} ; P$ is the designed wet soil ratio, $0.8 ; \beta_{1}$ is the field water holding capacity, $13.18 \%$ in $0-40 \mathrm{~cm}$ soil depth, $17.45 \%$ in $40-80 \mathrm{~cm}$ soil depth; and $\beta_{2}$ is the lower limit of the soil moisture content, $65 \%$ of $\beta_{1}$ at the vegetative and coloring mature stages and $70 \%$ of $\beta_{1}$ at the flowering and fruit expansion stage.

\subsection{Observation Indicators}

\subsubsection{Meteorological Factors}

All meteorological data are automatically measured and recorded every $30 \mathrm{~min}$ using a Watchdog micro series (Spectrum Technologies Inc., Chicago, IL, USA) meteorological station in the middle of the greenhouse. The monitoring indicators includes air temperature $\left(T_{a}\right)$, relative humidity $(R H)$, solar radiation $\left(R_{a}\right)$ and other meteorological parameters. The vapor pressure deficit (VPD) was estimated by the RH and $T_{a}$ and was calculated by the modified Penman formula. The formula [35] was as follows (2):

$$
V P D=0.6108 \times \operatorname{EXP}\left(\frac{17.27 \times T_{a}}{T_{a}+237.3}\right) \times\left(1-\frac{R H}{100}\right)
$$


Table 3. Irrigation amount of grapevine under different cultivation stages.

\begin{tabular}{|c|c|c|c|c|}
\hline \multirow{2}{*}{ Cultivation Stage } & \multirow{2}{*}{ Irrigation Date } & \multicolumn{3}{|c|}{ Irrigation Amount $\left(\mathrm{m}^{3} \cdot \mathrm{ha}^{-1}\right)$} \\
\hline & & $T_{1}$ & $\mathbf{T}_{2}$ & $\mathbf{T}_{3}$ \\
\hline \multirow{4}{*}{ vegetative stage } & $3 / 11$ & 293.61 & 234.80 & 176.02 \\
\hline & $3 / 19$ & 293.61 & 234.65 & 175.55 \\
\hline & $3 / 27$ & 293.60 & 234.60 & 175.34 \\
\hline & $4 / 06$ & 293.62 & 234.65 & 175.62 \\
\hline \multirow{2}{*}{ Flowering stage } & $4 / 15$ & 341.40 & 273.05 & 204.60 \\
\hline & $4 / 25$ & 341.39 & 273.04 & 204.15 \\
\hline \multirow{4}{*}{ Fruit expansion stage } & $5 / 05$ & 341.39 & 273.00 & 204.20 \\
\hline & $5 / 13$ & 341.37 & 272.58 & 204.14 \\
\hline & $5 / 20$ & 341.42 & 272.69 & 204.47 \\
\hline & $5 / 27$ & 341.41 & 273.10 & 204.34 \\
\hline \multirow{2}{*}{ Coloring mature stage } & $6 / 05$ & 293.60 & 234.50 & 175.59 \\
\hline & $6 / 15$ & 293.61 & 234.55 & 176.30 \\
\hline \multicolumn{2}{|c|}{ Total irrigation amount } & 3810 & 3045 & 2280 \\
\hline
\end{tabular}

\subsubsection{Soil Moisture Content}

The soil moisture automatic monitoring system consisted of an EM50 data recorder (Environmental Logging System, Decision Devices, Inc., Pullman, WA, USA) and four $\mathrm{ECH}_{2} \mathrm{O}_{5} \mathrm{TE}$ sensors (Decision Devices, Pullman, WA, USA). The soil moisture automatic monitoring system was installed $30 \mathrm{~cm}$ from the base of the grapevines and perpendicular to the planting row. Three representative grapevines were selected, and three monitoring systems were installed for each treatment. A sensor was installed every $20 \mathrm{~cm}$, the buried depth was $80 \mathrm{~cm}$, the soil volume moisture content was recorded every $30 \mathrm{~min}$. Before the beginning of the growing season, in order to ensure the accuracy of the $\mathrm{ECH}_{2} \mathrm{O}_{5} \mathrm{TE}$ sensor, soil samples were taken every $20 \mathrm{~cm}$ with a soil drill until $80 \mathrm{~cm}$, and the soil moisture content was calculated by drying method. At the same time, the data recorded by the $\mathrm{ECH}_{2} \mathrm{O}_{5} \mathrm{TE}$ sensor in different soil layers were recorded. Three days of soil moisture data were used to calibrate $\mathrm{ECH}_{2} \mathrm{O}_{5} \mathrm{TE}$ by drying method. The regression equation was established by regression analysis between the soil water content calculated by drying method and the soil water content monitored by $\mathrm{ECH}_{2} \mathrm{O}_{5} \mathrm{TE}$. In addition, the same method was used to calibration $\mathrm{ECH}_{2} \mathrm{O}_{5} \mathrm{TE}$ every 10 days during grape growth.

\subsubsection{Stem Diameter Microchanges}

The stem diameter microchanges were automatically monitored continuously using a DEX20 (Dynamax, USA, $0.050 \mathrm{~mm}$ ) instrument. The instrument was installed at the stem $10 \mathrm{~cm}$ above the ground, with a maximum displacement of $5 \mathrm{~mm}$ and a recording interval of $30 \mathrm{~min}$. The relative variation (RV) in stem diameter was defined as the change value at the time of probe installation, and the grapevine stem diameters were inconsistent when the sensor was installed due to differences among different plants. To explain the difference in plant growth caused by different water treatments, the initial value of stem diameter at the time of sensor installation in each growth period was set to $1 \mathrm{~mm}$, so that the three treatments could be compared easily. The maximum daily shrinkage (MDS) was calculated by subtracting the minimum stem diameter (MNSD) from the maximum stem diameter (MXSD). Periodic changes in stem diameter were observed daily; MXSD usually occurred in the early morning and MNSD occurred at noon. The daily increase (DI) of stem diameter was obtained by subtracting the daily MXSD from that of the day before.

\subsubsection{Stem Water Potential and Relative Water Content of Leaves}

The pressure chamber (TP-PW-II, Top Cloud-agri Technology Company, Zhejiang, China) was used to measure the stem water potential $\left(\varphi_{s}\right)$ every 5-7 days, and the $\varphi_{s}$ is measured at 9:00 to 10:00 BJS. Three grapevines were selected for each treatment, and 
one branch under good growth conditions was selected as the sample on the sunny side outside the crown. The sample was put into a plastic bag containing moist gauze and quickly brought into the laboratory. The sample was clamped in a pressure chamber and pressurized by gas (compressed nitrogen), the pressure used for exudation of tissue fluid was observed. At this time, the pressure value was the stem water potential.

The relative water content (RWC) of leaves was determined by the drying method. The selection and determination of leaves were the same as those used for leaf water potential measurement. After weighing the fresh weight, the leaves were immersed in water for $12 \mathrm{~h}$ and then taken out. The water on the surface of the leaves was wiped with absorbent paper and weighed. Then, the leaves were immersed in water for $1 \mathrm{~h}$, taken out, wiped dry and weighed until reaching a consistent weight. After $0.5 \mathrm{~h}$ of dehumidification at $105^{\circ} \mathrm{C}$ for $0.5 \mathrm{~h}$, the leaves were dried to constant weight at $80^{\circ} \mathrm{C}$. Leaf relative water content $($ RWC $)=($ initial fresh weight - dry weight $) /($ saturated fresh weight - dry weight $)$ $\times 100 \%$.

\subsubsection{Signal Intensity Calculation of Stem Diameter Indicator}

The reference value is usually calculated by the stem diameter indicator under nonwater stressed conditions or by substituting the meteorological indicator into the reference equation [21]. The calculation formulas of $\mathrm{SI}_{\mathrm{MDS}}$ and $\mathrm{SI}_{\mathrm{DI}}$ are as follows:

$$
\begin{aligned}
\mathrm{SI}_{\mathrm{MDS}} & =\text { Measured MDS } / \text { Reference MD } \\
\mathrm{SI}_{\mathrm{DI}} & =\text { Measured DI } / \text { Reference DI }
\end{aligned}
$$

In this study, the regression equation between the MDS and DI of stem diameter and meteorological factors showed that the correlation between the MDS and DI of three treatments and $\mathrm{T}_{\mathrm{a}}$ was the best. The soil moisture of the $\mathrm{W} 1$ treatment always remained above $65 \%$ of the field capacity at the vegetative and mature stages and $70 \%$ of the field capacity at the flowering stage and fruit expansion stage. The reference equation for stem diameter was established between the MDS and DI values of the $\mathrm{W} 1$ and $\mathrm{T}_{\mathrm{a}}$ to calculate the reference value of MDS and DI for each growth stage.

\subsubsection{Flexible Evaluation of Signal Intensity}

High variability indicators need to be measured many times to reduce error, which increases the costs of such methods. Therefore, the intensity and variability (coefficient of variance, $\mathrm{CV}$ ) of indicators should also be considered. When soil moisture changes, the ratio of signal intensity (SI) to noise is greater in the short term, indicating that the indicator is more suitable for moisture status diagnosis [36]. The formula for calculating the signal-to-noise ratio is shown in formula (5).

$$
\text { Signal-to-noise ratio }=\text { signal intensity } / \text { coefficient of variation }
$$

\subsection{Data Analysis}

The correlation and regression analysis were carried out using SPSS 21.0 software (SPSS Inc., Chicago, IL, USA). Multiple comparisons were performed by least significant difference tests, with a significance level of 0.05. Microsoft Excel 2010 Software was used for processing data. The graphs were created by using Origin 2018. Correlation analysis was conducted between MDS, DI, SI $\mathrm{SI}_{\mathrm{DI}} \mathrm{SI}_{\mathrm{MDS}}$ and meteorological factors; The relationships between MDS, DI, $\mathrm{SI}_{\mathrm{DI}}, \mathrm{SI}_{\mathrm{MDS}}$ and SWP, RWC as well as between MDS, $\mathrm{DI}, \mathrm{SI}_{\mathrm{DI}}, \mathrm{SI}_{\mathrm{MDS}}$ and soil water content were analyzed through regression analyses. In all cases, the coefficient of determination $\left(R^{2}\right)$ was used to assess the goodness of fit of the associations among variables. 


\section{Results}

\subsection{The Relative Variation of Stem Diameter under Different Stages}

The relative variation (RV) curve of stem diameter under different stages showed a $24 \mathrm{~h}$ up and down cycle, and different irrigation amounts had different influences on the stem diameter of grapevine (Figure 1). The total increase in stem diameter was $0.128 \mathrm{~mm}$ under W1, while those of W2 and W3 fluctuated and decreased. The stem diameter of W3 began to decrease sharply after 7 April, and the total increase in stem diameter under $\mathrm{W} 2$ and $\mathrm{W} 3$ was -0.143 and $-0.570 \mathrm{~mm}$, respectively (Figure 1a). There was a certain difference in the RV curve between the vegetative and flowering stages, and the RV curves of stem diameter under three treatments showed an up and down growth trend (Figure 1b). In terms of the total increase in stem diameter, W1 was the largest $(0.555 \mathrm{~mm})$, and W2 and W3 showed values $69.55 \%$ and $32.79 \%$ of that under W1, respectively.
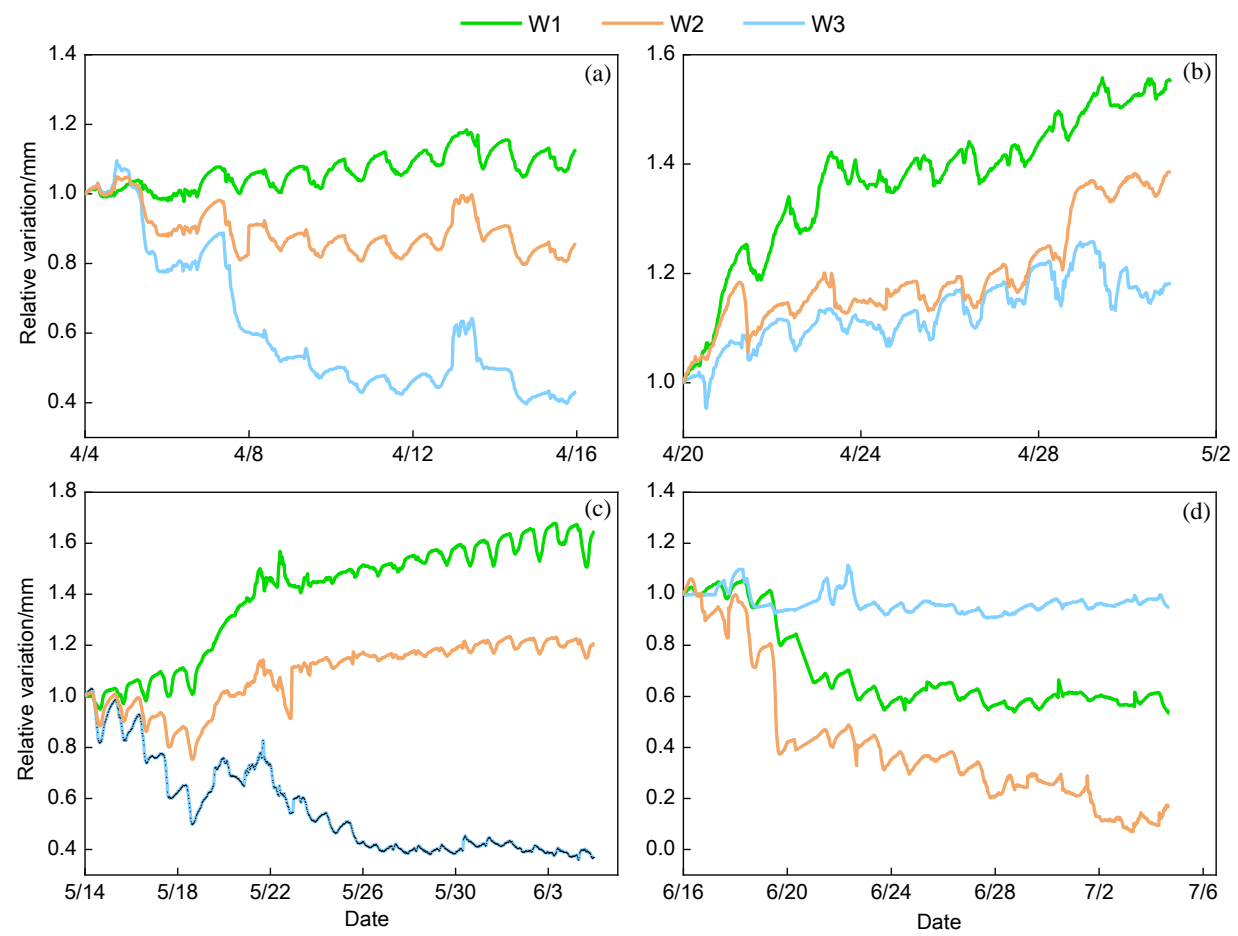

Figure 1. Relative variation curve of stem diameter during different stages. (a) Represents the vegetative stage, (b) represents the flowering stage, (c) represents the fruit expansion stage, and (d) represents the coloring mature stage.

There were significant differences in the RV curve of stem diameter among different treatments during the fruit expansion stage (Figure 1c). The RV curve of W1 showed an upward trend, and the RV curve of W2 fluctuated by approximately $1 \mathrm{~mm}$. Before irrigation on 20 May, the RV curve of the W3 treatment showed a decreasing fluctuating trend, the diameter of the stem recovered after irrigation, and the recovery effect gradually weakened when the soil moisture content gradually decreased. The stem diameter recovered values under W2 and W3 were $86.28 \%$ and $72.79 \%$ of that under W1, respectively. The stem diameter RV under W3 remained stable at approximately $0.4 \mathrm{~mm}$ after 25 May. The RV curve of W1 and W2 showed a decreasing trend during the mature stage (Figure 1d), the $\mathrm{RV}$ curve of W3 fluctuated at $1 \mathrm{~mm}$, but the three treatments still had significant shrinkage. The contractions under W1 and W2 were more pronounced than those under W3. The total increase in stem diameter among the three treatments was negative.

The daily change of stem diameter was the same under three treatments (Figure 2), it showed a trend of first increasing, then decreasing, and then increasing over $24 \mathrm{~h}$. The MDS of the stem diameter showed significant differences under three treatments. The MDS of 
W3 was the largest at $0.138 \mathrm{~mm}$, and W1 was the lowest at $0.051 \mathrm{~mm}$. The stem diameter of W1 could recovered to the maximum of the previous day and continued to grow. However, the stem diameter under W2, W3 could not recover to the maximum of the previous day owing to moisture stress, and growth of both W1 and W2 appeared negative. The MXSD and MNSD of three treatments appeared at the same time on rainy days, which included that rainy weather had no significant effect on the occurrence time of MXSD and MXSD under different treatments. The variation in $\mathrm{R}_{a}, \mathrm{~T}_{\mathrm{a}}$ and $\mathrm{RH}$ on rainy days was smaller than that on sunny days, and the degree of stem diameter contraction was also lower on rainy days than that on sunny days, which showed meteorological factors may be the main force affecting the variation in stem diameter. We can conclude that MDS decreased with increasing irrigation amount, the influence of meteorological factors and soil moisture on the variation in stem diameter was interactive.

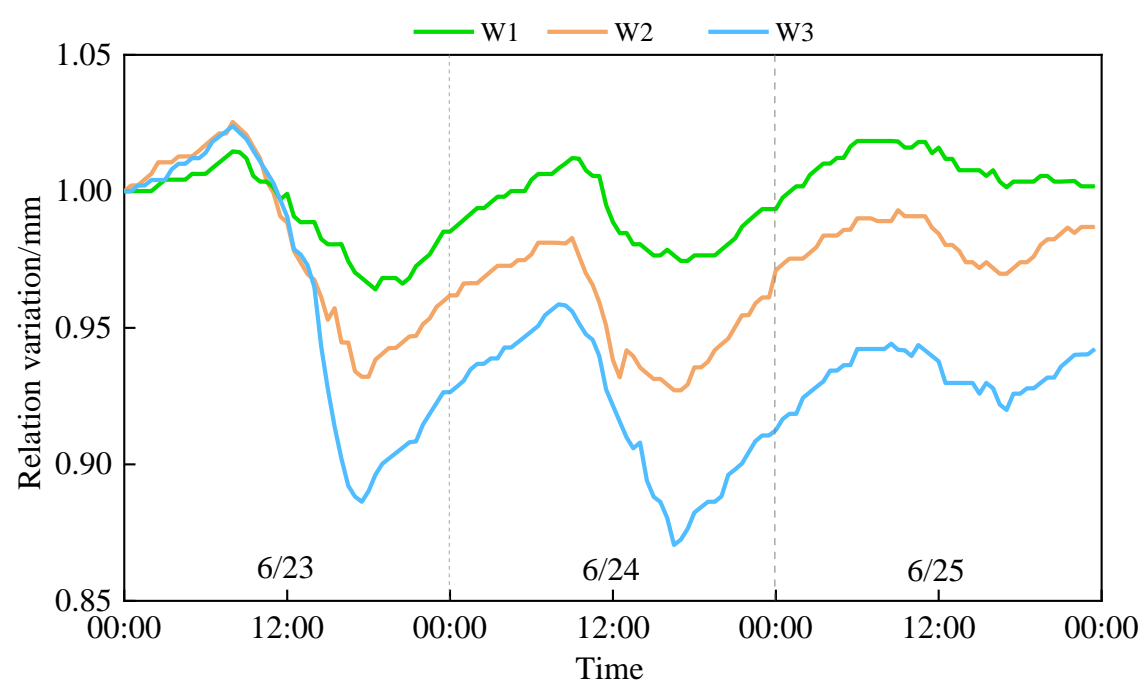

Figure 2. The daily change in stem diameter of grapevine under different weathers. Sunny days: 6/23, 6/24; Rainy day: 6/25.

\subsection{Evaluation of Applicability as a Moisture Diagnosis Indicator}

\subsubsection{The Correlation of MDS and DI with Meteorological Factors}

The MDS and DI are the main components of stem diameter variation and are affected by soil moisture and meteorological factors [22]. Correlation analysis was carried out between MDS (Figure 3) and DI (Figure 4) in stem diameter and meteorological factors. The change in MDS was similar to those in meteorological factors $\left(R_{a}, T_{a}\right.$ and VPD). The MDS increased with increasing $R_{a}, T_{a}$ and VPD and decreased with increasing $R H$. The correlation of DI with meteorological factors was opposite to that of MDS. The correlations between the MDS and DI of the three treatments and meteorological factors were significant $(p<0.05)$. The correlation between MDS and meteorological factors decreased with increasing irrigation, and the correlation between the DI and meteorological factors increased with increasing irrigation. It can be seen from Table 4 that the correlation coefficients of MDS, DI and $\mathrm{T}_{\mathrm{a}}$ were the highest, at $0.601-0.692$ and $0.683-0.723$, respectively.

\subsubsection{The Correlation of MDS, DI with Stem Water Potential and RWC of Leaves}

Stem water potential (SWP) and relative water content (RWC) of leaves are important indicators to characterize plant water status and exhibit the most direct response to drought during crop growth $[37,38]$. The models of MDS, DI and SWP and RWC were established. The coefficient of determination $\left(R^{2}\right)$ is shown in Table 5 . The regression equations of MDS and DI with SWP and RWC generally meet the significance test, which shows that both MDS and DI have obvious correlation with SWP and RWC, but $\mathrm{R}^{2}$ values are not high. We found that, compared with W1 and W2, the $R^{2}$ values of MDS with SWP and RWC in W3 treatment were below 0.20, and the significance was weak. Therefore, MDS and DI were 
easily disturbed by meteorological factors and could not be directly used for the diagnosis of grapevine water status.
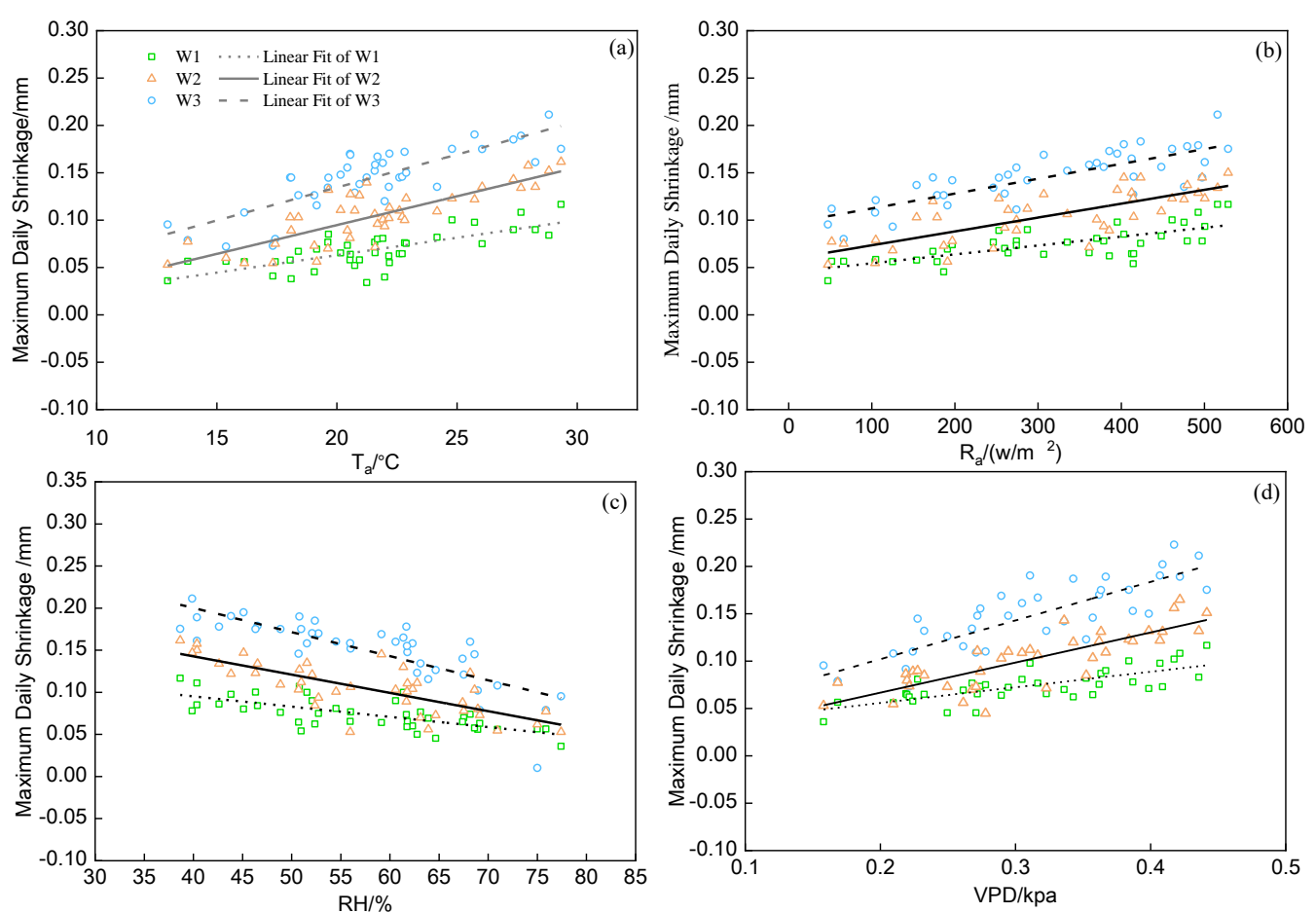

Figure 3. The relationship of MDS with $\mathrm{T}_{\mathrm{a}}(\mathbf{a}), \mathrm{R}_{\mathrm{a}}(\mathbf{b}), \mathrm{RH}(\mathbf{c})$ and $\operatorname{VPD}(\mathbf{d})$.
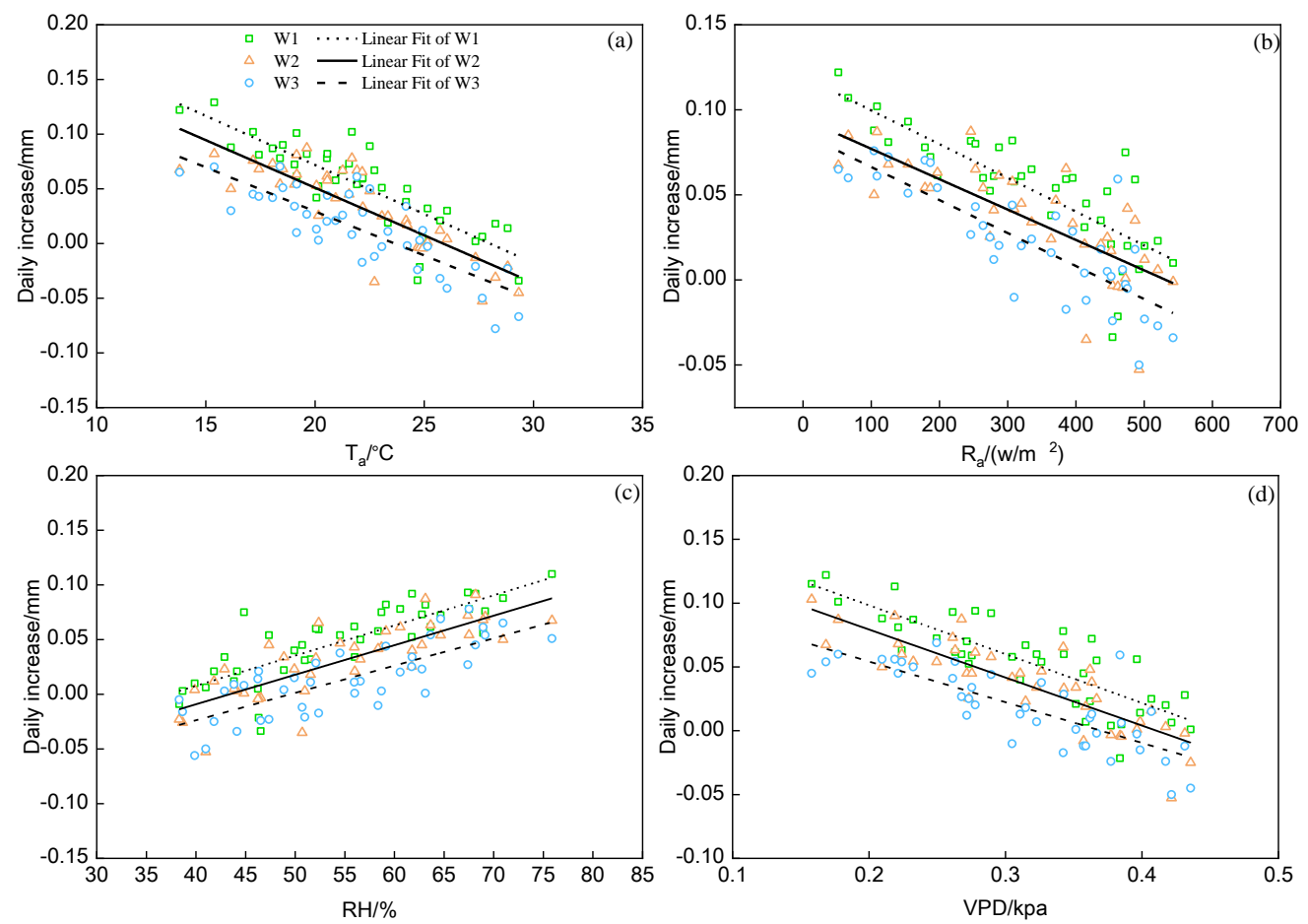

Figure 4. The relationship of DI with $\mathrm{T}_{\mathrm{a}}(\mathbf{a}), \mathrm{R}_{\mathrm{a}}(\mathbf{b}), \mathrm{RH}(\mathbf{c})$ and VPD (d). 
Table 4. Correlation analysis of MDS and DI in different stages under different treatments.

\begin{tabular}{ccccccccc}
\hline \multirow{2}{*}{ Treatment } & \multicolumn{2}{c}{ Air Temperature } & \multicolumn{2}{c}{ Solar Radiation } & \multicolumn{2}{c}{ Relative Humidity } & \multicolumn{2}{c}{$\begin{array}{c}\text { Vapor Pressure } \\
\text { Difference }\end{array}$} \\
\cline { 2 - 9 } & MDS & DI & MDS & DI & MDS & DI & MDS & DI \\
\hline W1 & $0.601^{* *}$ & $0.723^{* *}$ & $0.534^{* *}$ & $0.671^{* *}$ & $0.498^{* *}$ & $0.672^{* *}$ & $0.547^{* *}$ & $0.705^{* *}$ \\
W2 & $0.674^{* *}$ & $0.710^{* *}$ & $0.594^{* *}$ & $0.606^{* *}$ & $0.585^{* *}$ & $0.663^{* *}$ & $0.673^{* *}$ & $0.721^{* *}$ \\
W3 & $0.692^{* *}$ & $0.683^{* *}$ & $0.642^{* *}$ & $0.664^{* *}$ & $0.635^{* *}$ & $0.623^{* *}$ & $0.686^{* *}$ & $0.631^{* *}$ \\
\hline
\end{tabular}

Note: The correlation between MDS and meteorological factors. ${ }^{* *}$ Correlation is significant at the 0.01 level.

Table 5. Stem water potential and leaf relative water content model with MDS and DI.

\begin{tabular}{|c|c|c|c|c|c|c|}
\hline \multirow{2}{*}{ Index } & \multicolumn{3}{|c|}{ Stem Water Potential } & \multicolumn{3}{|c|}{ Relative Water Content of Leaves } \\
\hline & Model & $\mathbf{R}^{2}$ & $p$ & Model & $\mathbf{R}^{2}$ & $p$ \\
\hline \multirow{3}{*}{ MDS } & $\mathrm{SWP}_{\mathrm{W} 1}=-0.162 \mathrm{MDS}+0.027$ & $0.338 *$ & 0.023 & $\mathrm{RWC}_{\mathrm{W} 1}=-0.004 \mathrm{MDS}+0.438$ & $0.315 *$ & 0.030 \\
\hline & $\mathrm{SWP}_{\mathrm{W} 2}=-0.302 \mathrm{MDS}-0.024$ & $0.498 * *$ & 0.003 & $\mathrm{RWC}_{W 2}=-0.014 \mathrm{MDS}+1.204$ & $0.385 *$ & 0.014 \\
\hline & $\mathrm{SWP}_{\mathrm{W} 3}=-0.064 \mathrm{MDS}+0.017$ & 0.144 & 0.163 & $\mathrm{RWC}_{\mathrm{W} 3}=-0.010 \mathrm{MDS}+0.837$ & 0.167 & 0.130 \\
\hline \multirow{3}{*}{ DI } & $\mathrm{SWP}_{\mathrm{W} 1}=0.215 \mathrm{DI}+0.105$ & $0.391 *$ & 0.013 & $\mathrm{RWC}_{\mathrm{W} 1}=0.005 \mathrm{DI}-0.382$ & $0.296 *$ & 0.036 \\
\hline & $\mathrm{SWP}_{\mathrm{W} 2}=0.126 \mathrm{DI}+0.081$ & 0.356 * & 0.019 & $\mathrm{RWC}_{W 2}=0.006 \mathrm{DI}-0.484$ & $0.338 *$ & 0.023 \\
\hline & $\mathrm{SWP}_{\mathrm{W} 3}=0.023 \mathrm{DI}+0.046$ & $0.299 *$ & 0.035 & $\mathrm{RWC}_{\mathrm{W} 3}=0.005 \mathrm{DI}-0.308$ & $0.410 *$ & 0.010 \\
\hline
\end{tabular}

* indicates a significance level of $p=0.05 ; * *$ indicates a significance level of $p=0.01$.

\subsubsection{The Correlation of MDS and DI with Soil Moisture under Different Stages}

Soil moisture has been widely used as an indirect index of crop water deficit. It can be used to diagnose crop moisture status if stem diameter variation is sensitive to soil moisture. Regression analysis was carried out between MDS and DI in stem diameter and soil moisture (Figure 5). It can be concluded that the response of DI to soil moisture was more sensitive during the flowering stage, while that of MDS was more sensitive during the fruit expansion stage. In general, the $\mathrm{R}^{2}$ values of the MDS and DI models were low under different treatments. The reason for this result is that the MDS and DI in grapevine stem diameter were easily affected by meteorological factors. Therefore, combined with the above conclusion, it is necessary to eliminate the interference of meteorological factors on the stem diameter variation.

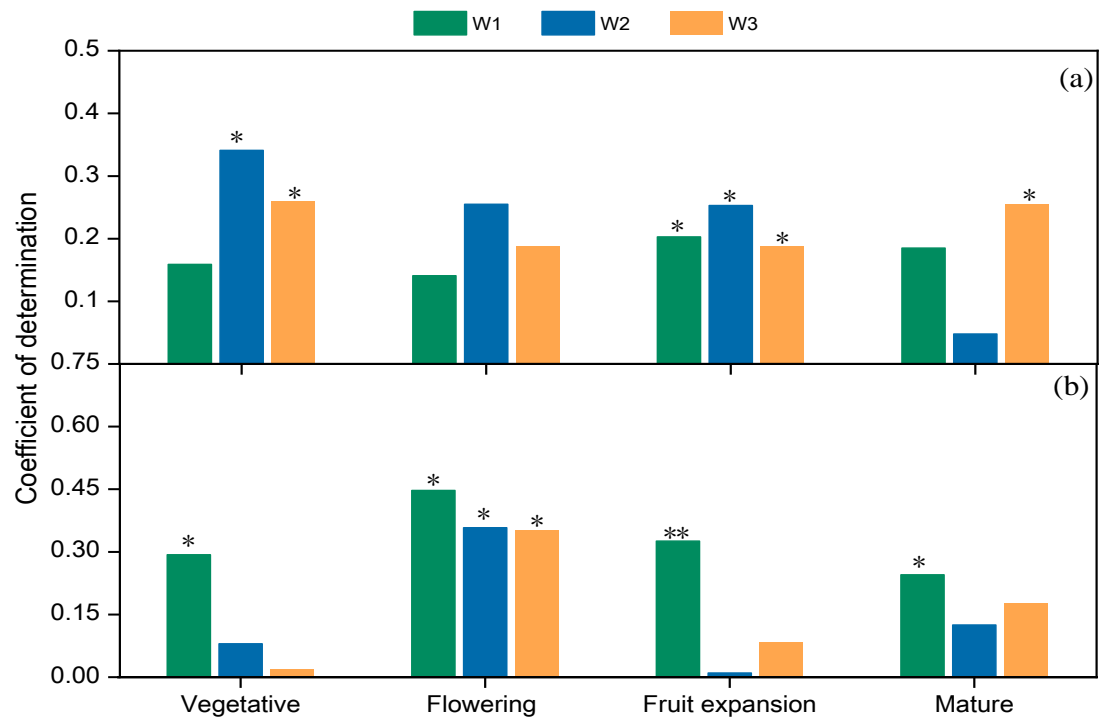

Figure 5. The correlation of MDS and DI with soil moisture content under different stages. (a) Represents the correlation of MDS with soil moisture content; (b) represents the correlation of DI with soil moisture content. * indicates a significance level of $p=0.05$; ${ }^{* *}$ indicates a significance level of $p=0.01$. 


\subsubsection{Signal Intensity of Stem Diameter Indicator}

The signal intensities of MDS ( $\left.\mathrm{SI}_{\mathrm{MDS}}\right)$ and DI ( $\left.\mathrm{SI}_{\mathrm{DI}}\right)$ under different treatments at

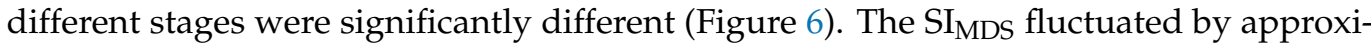
mately $1 \mathrm{~mm}$ from the vegetative stage to fruit expansion stage under $\mathrm{W} 1$, while it mostly fluctuated below $1 \mathrm{~mm}$ at the mature stage. The $\mathrm{SI}_{\mathrm{DI}}$ fluctuated approximately 1 under W1 during the whole growth period. The degree of change in $\mathrm{SI}_{\mathrm{MDS}}$ and $\mathrm{SI}_{\mathrm{DI}}$ under W2 and W3 increased sequentially, and the signal values of the same stage were larger than those of the W1. It can be seen that with the increase in irrigation, the $\mathrm{SI}_{\mathrm{DI}}$ and $\mathrm{SI}_{\mathrm{MDS}}$ values of stem diameter tended to become stable. The $\mathrm{SI}_{\mathrm{MDS}}$ of the three treatments peaked during the fruit expansion stage (Figure 6e), followed by the flowering stage (Figure 6c). The SI DI of the W3 dropped sharply to below 0 on 26 May and was restored after rehydration on 27 May. Compared with those under the other growth stages, the $\mathrm{SI}_{\mathrm{MDS}}$ and $\mathrm{SI}_{\mathrm{DI}}$ of each treatment decreased to different degrees at the mature stage (Figure 6g,h), and that of W3 treatment decreased most significantly. The $\mathrm{SI}_{\mathrm{MDS}}$ of the $\mathrm{W} 3$ decreased rapidly to below the W1 level within one week after irrigation stopped and then remained stable. The SI was difficult to use to distinguish the moisture status of grapevines at the mature stage due to the large fluctuation and instability of the signal values. In conclusion, $\mathrm{SI}_{\mathrm{MDS}}$ was preliminarily determined to be an appropriate indicator of plant moisture status, and $\mathrm{SI}_{\mathrm{DI}}$ can be used as an indicator of moisture status at stages other than the mature stage.

3.2.5. The Correlation of $\mathrm{SI}_{\mathrm{MDS}}$ and $\mathrm{SI}_{\mathrm{DI}}$ with Meteorological Factors, Stem Water Potential and RWC

The correlation coefficients of the $\mathrm{SI}_{\mathrm{MDS}}$ and $\mathrm{SI}_{\mathrm{DI}}$ with meteorological factors during different growth stages are shown in Figure 7. In addition, while the individual correlation coefficient reached a significant level, the correlation of the $\mathrm{SI}_{\mathrm{DI}}$ and $\mathrm{SI}_{\mathrm{MDS}}$ of three treatments with meteorological factors during the whole growth period was not significant (Figure 7), which indicated that the influence of meteorological factors on SI $\mathrm{DI}_{\mathrm{DI}}$ and $\mathrm{SI}_{\mathrm{MDS}}$ had been excluded.

It can be seen from Table 5 that the correlations between MDS and DI and SWP and RWC are relatively low. Therefore, after eliminating the interference of meteorological factors, the fitting diagrams and equations of $\mathrm{SI}_{\mathrm{MDS}}$ and $\mathrm{SI}_{\mathrm{DI}}$ with SWP and RWC are established (Figure 8 and Table 6). With the increase in $\mathrm{SI}_{\mathrm{MDS}}$, SWP under W3 decreased most significantly, RWC under W1 decreased most significantly; with the increase in $\mathrm{SI}_{\mathrm{DI}}$, SWP and RWC under W1 had the most significant increase. On the whole, the $\mathrm{R}^{2}$ of each equation was high, and the correlation reached a very significant level (Table 6). We concluded that the ability of $\mathrm{SI}_{\mathrm{MDS}}$ and $\mathrm{SI}_{\mathrm{DI}}$ to represent the deficit status of plants is greatly improved after eliminating the interference of meteorological factors.

Table 6. Stem water potential and leaf relative water content model with $\mathrm{SI}_{\mathrm{MDS}}$ and $\mathrm{SI}_{\mathrm{DI}}$.

\begin{tabular}{|c|c|c|c|c|c|c|}
\hline \multirow{2}{*}{ Index } & \multicolumn{3}{|c|}{ Stem Water Potential } & \multicolumn{3}{|c|}{ Relative Water Content of Leaves } \\
\hline & Model & $\mathbf{R}^{2}$ & $p$ & Model & $\mathbf{R}^{2}$ & $p$ \\
\hline \multirow{3}{*}{$\mathrm{SI}_{\mathrm{MDS}}$} & $\mathrm{SWP}_{\mathrm{W} 1}=-0.221 \mathrm{SI}_{\mathrm{MDS}}-0.025$ & $0.723 * * *$ & $<0.001$ & $\mathrm{RWC}_{\mathrm{W} 1}=-0.100 \mathrm{SI}_{\mathrm{DI}}+0.951$ & $0.710 * * *$ & $<0.001$ \\
\hline & $\mathrm{SWP}_{\mathrm{W} 2}=-0.362 \mathrm{SI}_{\mathrm{MDS}}+0.017$ & $0.762 * * *$ & $<0.001$ & $\mathrm{RWC}_{\mathrm{W} 2}=-0.045 \mathrm{SI}_{\mathrm{DI}}+0.861$ & $0.695^{* * *}$ & $<0.001$ \\
\hline & $\mathrm{SWP}_{\mathrm{W} 3}=-0.484 \mathrm{SI}_{\mathrm{MDS}}-0.711$ & $0.719 * * *$ & $<0.001$ & $\mathrm{RWC}_{\mathrm{W} 3}=-0.028 \mathrm{SI}_{\mathrm{DI}}+0.757$ & $0.599 * *$ & 0.001 \\
\hline \multirow{3}{*}{$\mathrm{SI}_{\mathrm{DI}}$} & $\mathrm{SWP}_{\mathrm{W} 1}=0.205 \mathrm{SI}_{\mathrm{MDS}}-0.386$ & $0.717 * * *$ & $<0.001$ & $\mathrm{RWC}_{W 1}=0.073 \mathrm{SI}_{\mathrm{DI}}+0.803$ & $0.705^{* * *}$ & $<0.001$ \\
\hline & $\mathrm{SWP}_{\mathrm{W} 2}=0.101 \mathrm{SI}_{\mathrm{MDS}}-0.519$ & $0.691 * * *$ & $<0.001$ & $\mathrm{RWC}_{\mathrm{W} 2}=0.024 \mathrm{SI}_{\mathrm{DI}}+0.776$ & $0.685^{* * *}$ & $<0.001$ \\
\hline & $\mathrm{SWP}_{\mathrm{W} 3}=0.172 \mathrm{SI}_{\mathrm{MDS}}-1.633$ & $0.640 * * *$ & $<0.001$ & $\mathrm{RWC}_{\mathrm{W} 3}=0.015 \mathrm{SI}_{\mathrm{DI}}+0.700$ & $0.660 * * *$ & $<0.001$ \\
\hline
\end{tabular}

Note: ${ }^{* *}$ indicates a significance level of $p=0.01 ;{ }^{* * *}$ indicates a significance level of $p<0.001$. 

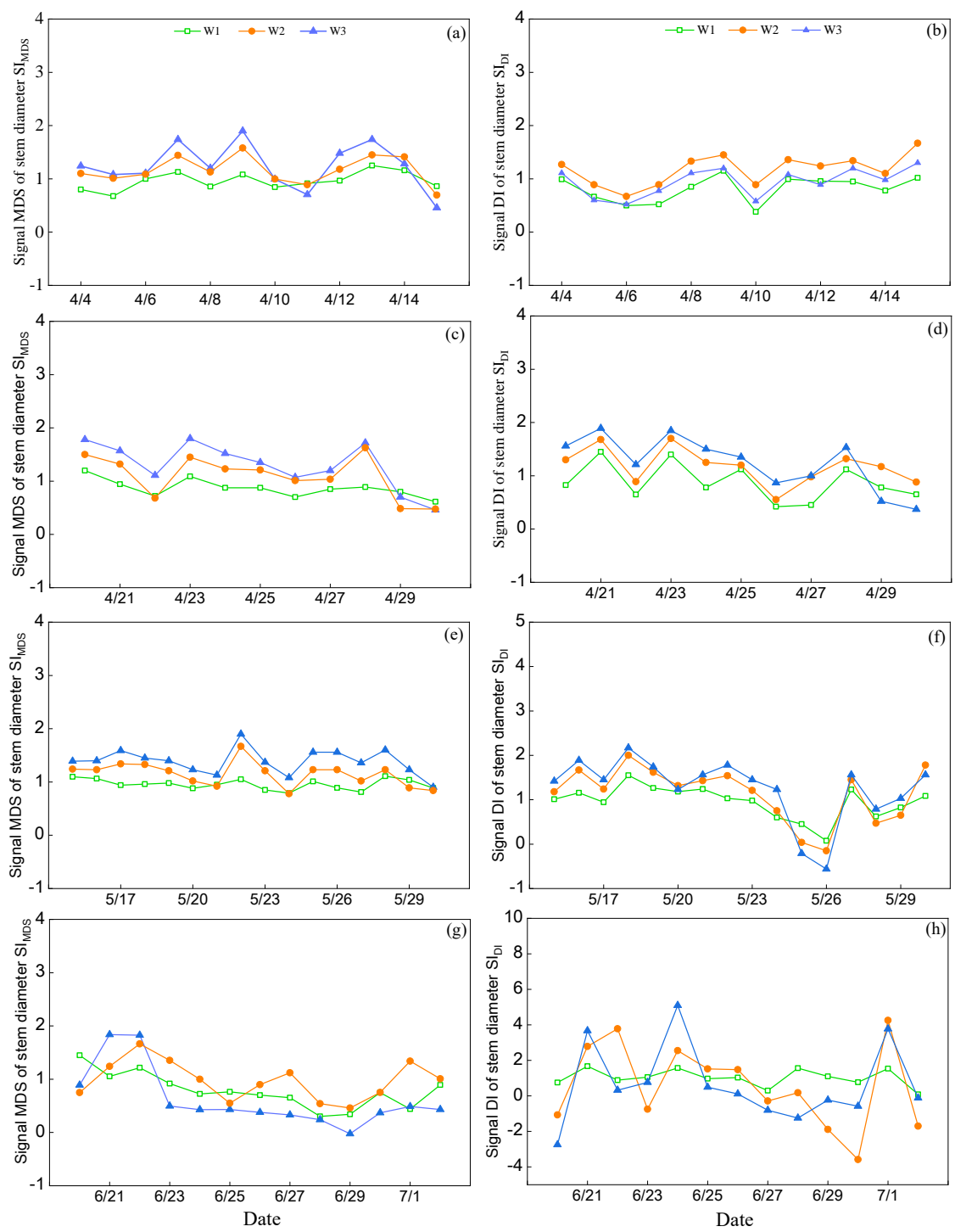

Figure 6. The change in $\mathrm{SI}_{\mathrm{MDS}}$ and $\mathrm{SI}_{\mathrm{DI}}$ under different stages of grapevine. $\mathrm{SI}_{\mathrm{MDS}}$ represents signal MDS of stem diameter, and $\mathrm{SI}_{\mathrm{DI}}$ represents signal DI of stem diameter. (a,c,e,g) Represents $\mathrm{SI}_{\mathrm{MDS}}$ at the vegetative, flowering, fruit expansion and mature stage, respectively. $(\mathbf{b}, \mathbf{d}, \mathbf{f}, \mathbf{h})$ Represents $\mathrm{SI}_{\mathrm{DI}}$ at the vegetative, flowering, fruit expansion and mature stage, respectively.

\subsubsection{Adaptable Evaluation of Signal Intensity under Different Stages}

In addition to using signal intensity of stem diameter to characterize the water status of plants, the signal intensity of stem diameter was also explored to monitor soil water content and diagnose whether grapevines were under water stress in real time. Therefore, the regression model between the $\mathrm{SI}_{\mathrm{MDS}}$ and $\mathrm{SI}_{\mathrm{DI}}$ of stem diameter and soil moisture was established (Table 7). It can be seen from Table 7 that the determination coefficient $\left(R^{2}\right)$ of the $\mathrm{SI}_{\mathrm{MDS}}$ model under three treatments were high during the growth stage, which indicated that $\mathrm{SI}_{\mathrm{MDS}}$ showed a good diagnostic effect on soil moisture status. The $\mathrm{R}^{2}$ of the $\mathrm{SI}_{\mathrm{DI}}$ model was higher at the vegetative and flowering stages, and $\mathrm{R}^{2}$ decreased to $0.022-0.232(p>0.05)$ at the mature stage. We can conclude that $\mathrm{SI}_{\mathrm{MDS}}$ and $\mathrm{SI}_{\mathrm{DI}}$ were more suitable for diagnosing soil water status than MDS and DI. However, the diagnostic effect of the two indicators was quite different under different stages, so it is necessary to further consider the moisture sensitivity under different stages to select the optimum indicator. 


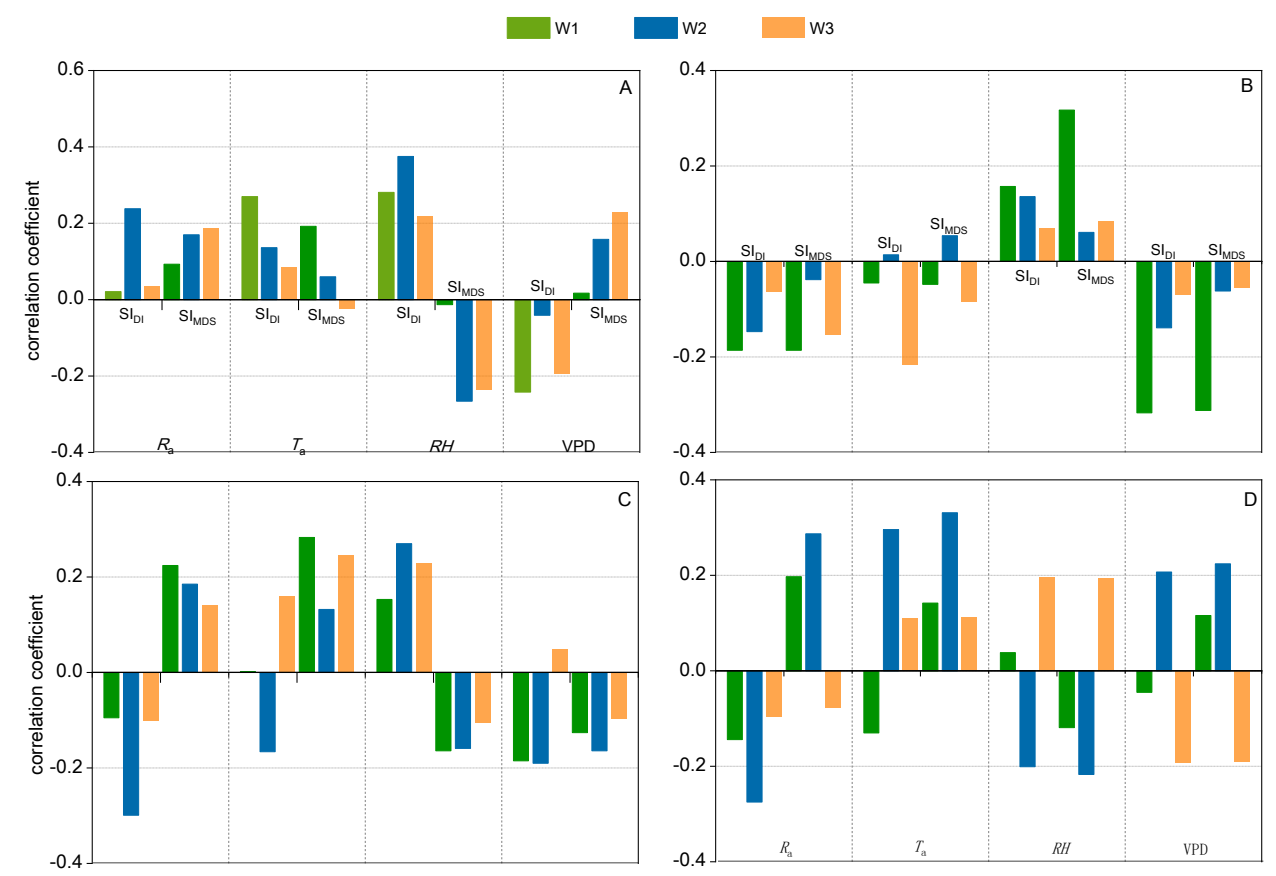

Figure 7. The correlation coefficients between $\mathrm{SI}_{\mathrm{MDS}}, \mathrm{SI}_{\mathrm{DI}}$ and meteorological factors under different treatments at different stages.
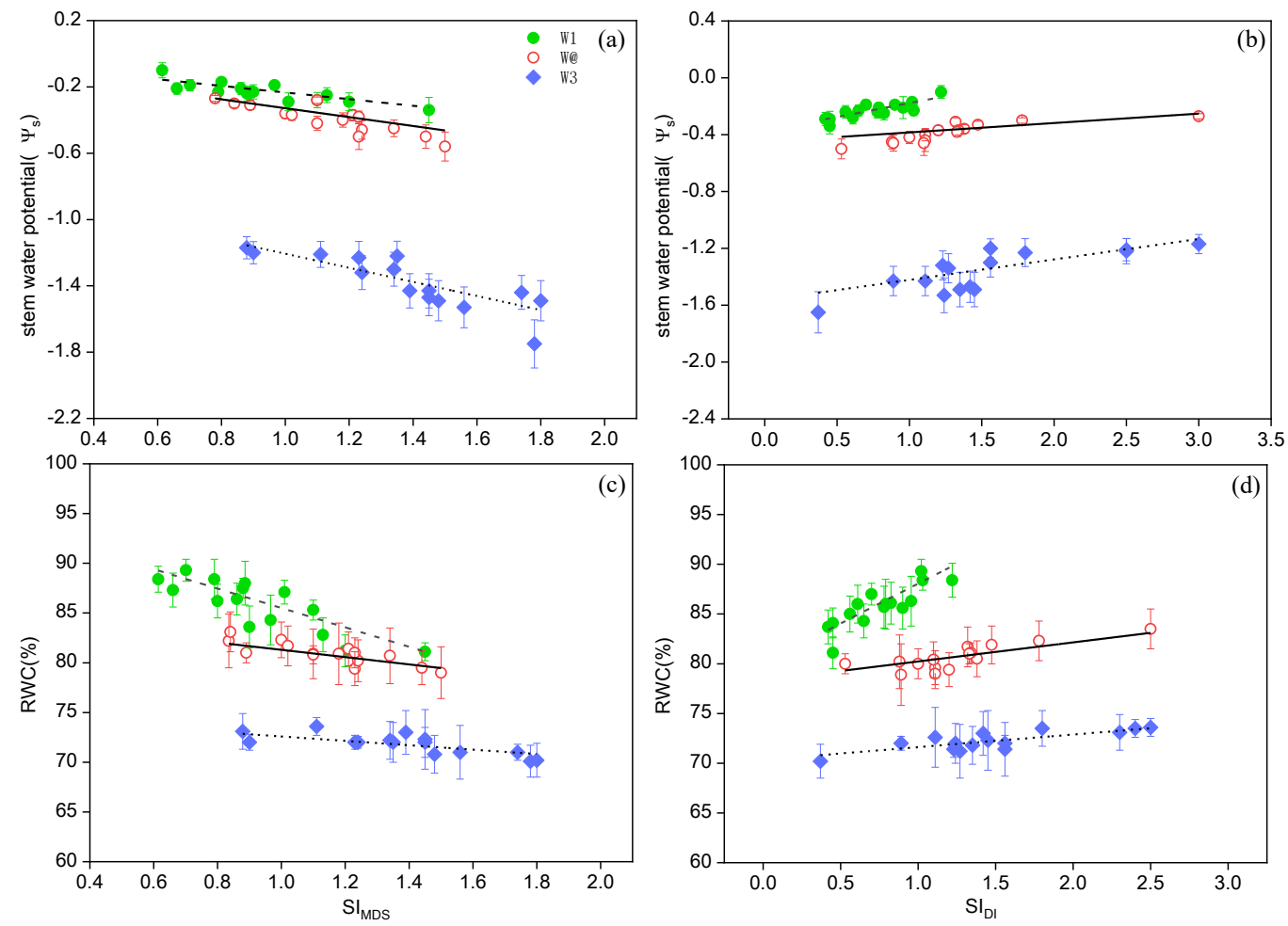

Figure 8. Relationships between $\mathrm{SI}_{\mathrm{MDS}}$ and $\mathrm{SI}_{\mathrm{DI}}$ and $\mathrm{SWP}$ and RWC under different treatments. (a) Represents the relationship between SWP and $\mathrm{SI}_{\mathrm{MDS}}$, (b) represents the relationship between SWP and $\mathrm{SI}_{\mathrm{DI}},(\mathbf{c})$ represents the relationship between RWC and $\mathrm{SI}_{\mathrm{MDS}}$, and (d) represents the relationship between RWC and SI $\mathrm{DI}$. 
Table 7. The model of $\mathrm{SI}_{\mathrm{DI}}$ and $\mathrm{SI}_{\mathrm{MDS}}$ with soil water content at different growth stages.

\begin{tabular}{|c|c|c|c|c|c|c|c|}
\hline Stage & Treatment & $\mathrm{SI}_{\mathrm{MDS}}$ & $\mathbf{R}^{2}$ & $p$ & $\mathbf{S I}_{\mathrm{DI}}$ & $\mathbf{R}^{2}$ & $p$ \\
\hline \multirow{3}{*}{ Vegetative stage } & W1 & $\mathrm{SI}_{\mathrm{MDS}}=-39.485 \theta+6.304$ & $0.688^{* * *}$ & $<0.001$ & $\mathrm{SI}_{\mathrm{DI}}=39.961 \theta-4.286$ & $0.739 * * *$ & $<0.001$ \\
\hline & W2 & $\mathrm{SI}_{\mathrm{MDS}}=-36.246 \theta+5.848$ & $0.566^{* * *}$ & $<0.001$ & $\mathrm{SI}_{\mathrm{DI}}=187.96 \theta-22.077$ & $0.448 *$ & 0.023 \\
\hline & W3 & $\mathrm{SI}_{\mathrm{MDS}}=-53.413 \theta+7.639$ & 0.358 & 0.067 & $\mathrm{SI}_{\mathrm{DI}}=162.48 \theta-19.697$ & $0.451 *$ & 0.019 \\
\hline \multirow{3}{*}{ Flowering stage } & W1 & $\mathrm{SI}_{\mathrm{MDS}}=-45.420 \theta+7.095$ & $0.514^{* * *}$ & $<0.001$ & $\mathrm{SI}_{\mathrm{DI}}=83.604 \theta-9.626$ & $0.631^{* * *}$ & $<0.001$ \\
\hline & W2 & $\mathrm{SI}_{\mathrm{MDS}}=-37.140 \theta+5.382$ & $0.652 * * *$ & $<0.001$ & $\mathrm{SI}_{\mathrm{DI}}=72.731 \theta-7.0531$ & $0.762 * * *$ & $<0.001$ \\
\hline & W3 & $\mathrm{SI}_{\mathrm{MDS}}=-18.224 \theta+3.042$ & $0.565^{* * *}$ & $<0.001$ & $\mathrm{SI}_{\mathrm{DI}}=137.85 \theta-14.041$ & $0.676^{* * *}$ & $<0.001$ \\
\hline \multirow{3}{*}{ Fruit expansion stage } & W1 & $\mathrm{SI}_{\mathrm{MDS}}=-37.788 \theta+5.795$ & $0.589 * * *$ & $<0.001$ & $\mathrm{SI}_{\mathrm{DI}}=37.116 \theta-3.687$ & $0.389 *$ & 0.038 \\
\hline & W2 & $\mathrm{SI}_{\mathrm{MDS}}=-34.848 \theta+4.983$ & $0.560 * * *$ & $<0.001$ & $\mathrm{SI}_{\mathrm{DI}}=27.010 \theta-3.140$ & 0.313 & 0.087 \\
\hline & W3 & $\mathrm{SI}_{\mathrm{MDS}}=-53.532 \theta-8.870$ & $0.575^{* * *}$ & $<0.001$ & $\mathrm{SI}_{\mathrm{DI}}=74.046 \theta-8.738$ & $0.495^{*}$ & 0.016 \\
\hline \multirow{3}{*}{ Mature stage } & W1 & $\mathrm{SI}_{\mathrm{MDS}}=-13.717 \theta+2.259$ & $0.409 *$ & 0.027 & $\mathrm{SI}_{\mathrm{DI}}=80.714 \theta-7.368$ & 0.022 & 0.433 \\
\hline & W2 & $\mathrm{SI}_{\mathrm{MDS}}=-94.494 \theta+12.967$ & $0.621^{* * *}$ & $<0.001$ & $\mathrm{SI}_{\mathrm{DI}}=143.48 \theta-15.637$ & 0.148 & 0.121 \\
\hline & W3 & $\mathrm{SI}_{\mathrm{MDS}}=-18.736 \theta+2.387$ & $0.646^{* * *}$ & $<0.001$ & $\mathrm{SI}_{\mathrm{DI}}=146.91 \theta-16.031$ & 0.232 & 0.885 \\
\hline
\end{tabular}

Note: $\theta$ represents the soil moisture content. ${ }^{*}$ indicates a significance level of $\mathrm{P}_{0.05} ;{ }^{* * *}$ indicates a significance level of $p<0.001$.

The signal intensity of MDS and DI ( $\left.\mathrm{SI}_{\mathrm{MDS}}, \mathrm{SI}_{\mathrm{DI}}\right)$ and the coefficient of variation of signal intensity under different stages are shown in Figure 9. The signal-to-noise ratio of $\mathrm{SI}_{\mathrm{MDS}}$ and $\mathrm{SI}_{\mathrm{DI}}$ under different treatments at different stages can be seen in Figure 10. The $\mathrm{SI}_{\mathrm{MDS}}$ and $\mathrm{SI}_{\mathrm{DI}}$ increased first and then decreased over the whole growth stage (Figure 9). We found that the average values of $\mathrm{SI}_{\mathrm{MDS}}$ and $\mathrm{SI}_{\mathrm{DI}}$ under different treatments were similar at the vegetative stage, but the variability of $\mathrm{SI}_{\mathrm{MDS}}$ was greater than that of SI $\mathrm{DI}_{\mathrm{DI}}$ (Figure 10), so $\mathrm{SI}_{\mathrm{DI}}$ was a more suitable diagnostic indicator of grapevine water status and soil water status during the vegetative stage. The average signal intensity, sensitivity and signal-tonoise ratio were similar at the flowering stage, but $\mathrm{SI}_{\mathrm{DI}}$ had a better correlation with soil moisture at the flowering stage (Table 7); thus, $\mathrm{SI}_{\mathrm{DI}}$ should be selected as the diagnostic indicator of grapevine water status and soil water status at the flowering stage. The signalto-noise ratio of $\mathrm{SI}_{\mathrm{MDS}}$ during the fruit expansion and the mature stages was higher than those of $\mathrm{SI}_{\mathrm{DI}}$ (Figure 10), and the sensitivity of $\mathrm{SI}_{\mathrm{MDS}}$ to soil moisture was better than that of $\mathrm{SI}_{\mathrm{DI}}$. Therefore, $\mathrm{SI}_{\mathrm{MDS}}$ was selected as the most suitable indicator of grapevine water status and soil water status during the fruit expansion and the mature stages.
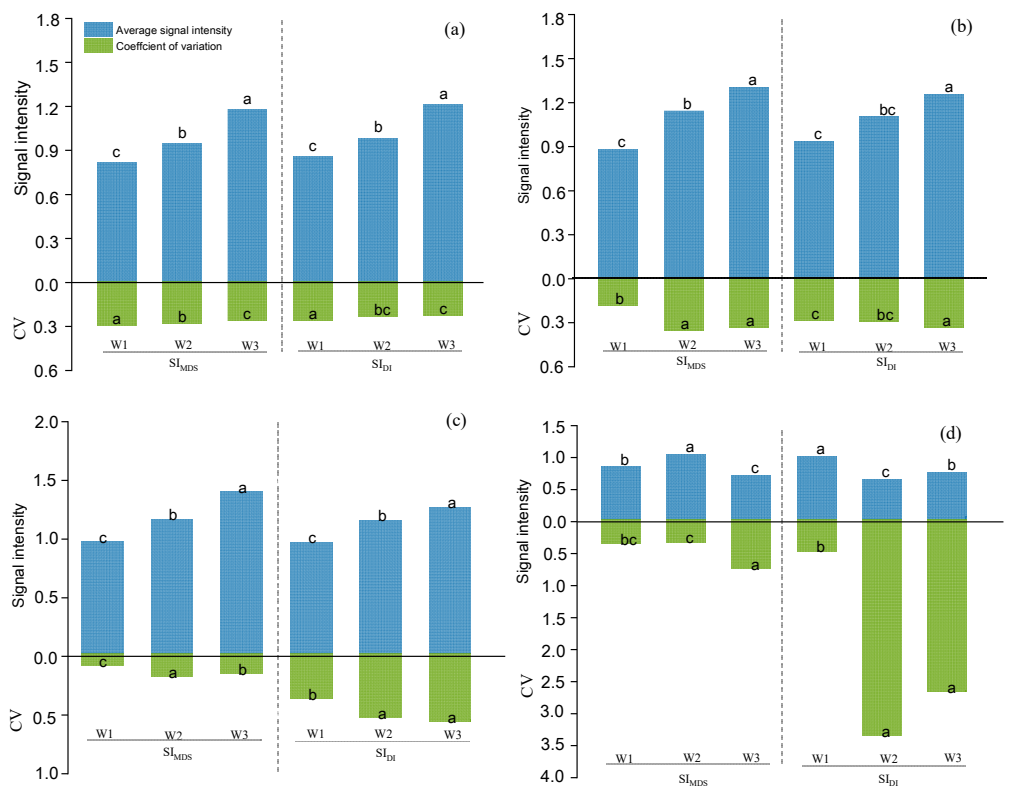

Figure 9. The average value of $\mathrm{SI}_{\mathrm{MDS}}$ and $\mathrm{SI}_{\mathrm{DI}}$ and coefficient of variation of signal strength under different growth stages. (a) Represents the vegetative stage, (b) represents the flowering stage, (c) represents the fruit expansion stage, and (d) represents the mature stage. Different lowercase letters indicate that there is a statistical difference at $\mathrm{P}_{0.05}$ under different treatments. 


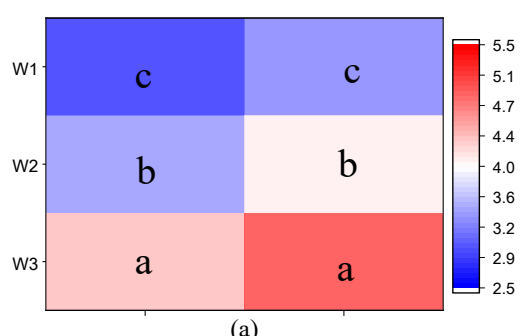

(a)

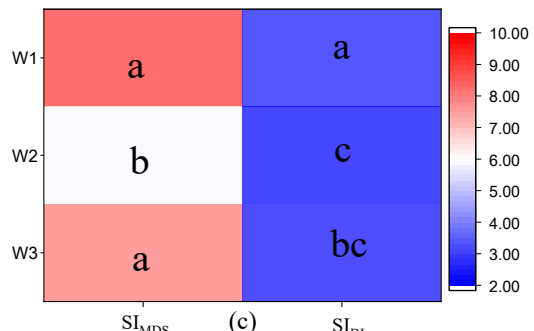

(c) $\quad \mathrm{SI}_{\mathrm{D}}$

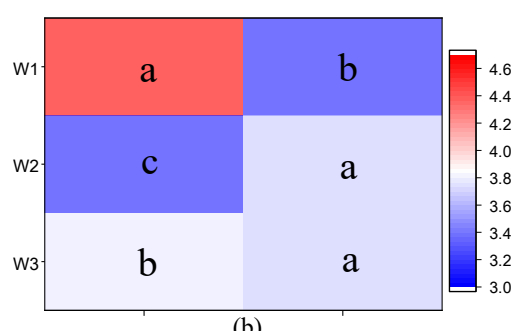

(b)

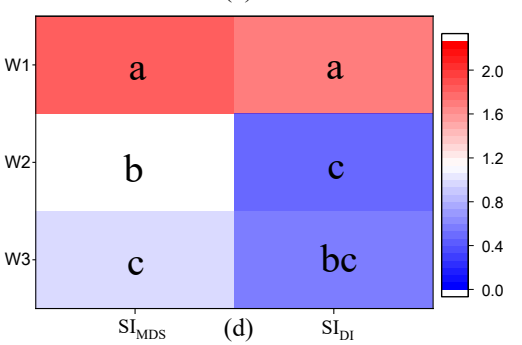

Figure 10. The signal-to-noise ratio of SIMDS and SIDI under different treatments at different stages. (a) Represents the vegetative stage, (b) represents the flowering stage, (c) represents the fruit expansion stage, and (d) represents the mature stage. Different lowercase letters indicate that there is a statistical difference of signal-to-noise ratio at $\mathrm{P}_{0.05}$ in the same column.

\section{Discussion}

\subsection{Relative Variation in Grapevine Stem Diameter}

To achieve sustainable water use and efficient cultivation of crops, the moisture condition of crops is an important factor. Under both high and low soil moisture conditions, the grapevine stems shrunk in the daytime and recovered or expanded at night, and the microchange in stem diameter was closely related to the water status of the plant [39,40]. The present study showed that the stem diameter under the W3 treatment began to decrease sharply after 7 April, and the total increase in stem diameter was $-0.570 \mathrm{~mm}$. Because the growth of new shoots mainly depends on the absorption of soil moisture and nutrients by the root system and transport of these nutrients to the new shoots, the soil moisture under the W3 treatment was low. When transpiration stopped at night, the moisture absorbed by the root system was not sufficient to make up for the transpiration loss during the day, so the increase in stem diameter stopped or stems even exhibited negative growth, similar to the results of Xiong [41].

The difference in the MDS among the three treatments was not significant during the vegetative and flowering stages. The reason for this phenomenon is that the rapid growth rate conceals the short-term variation in stem diameter caused by water deficit, which indicates that MDS is not a suitable indicator of moisture status during early grapevine development [42]. During the mature stage, the growth of the stems slowed with the seasonal process. At the fruit growth stage, the stems also ceased growth or shrunk without water stress $[43,44]$. The results showed that the relative variations in stem diameter among the three treatments decreased gradually, similar to the results of Intrigliolo and Castel [44] and Girón et al. [44]. With the increase in water stress, the MDS under the W3 treatment was the lowest at the flowering and fruit expansion stages. This effect may be the result of the combination of the degree of water stress on the plant and the ability of the tissue to hold water against the water potential gradient [12]. Further research is needed to more accurately explain these findings.

\subsection{The Correlations of MDS and DI with Meteorological Factors}

Numerous studies have shown that MDS is sensitive to soil and plant moisture status, and this measure has been applied in production as a key indicator to guide fruit tree irrigation [31,45-47]. The DI reflects the growth rate of the stem, which is affected by the water supply in the root zone and the intensity of transpiration. The DI is also 
sensitive to the plant moisture status during the rapid growth stage of crops. Therefore, it is particularly important to analyze stem diameter microchanges for diagnosing crop water deficit. Previous studies have shown that the key meteorological factors affecting stem diameter of fruit trees under outdoor conditions are daily mean water pressure deficit (VPD) or daily maximum temperature $\left(\mathrm{T}_{\max }\right)[16,23,48]$. In the current study, we found that $\mathrm{T}_{\max }$ and VPD are the key meteorological factors affecting MDS and DI, which is consistent with previous studies on outdoor fruit trees. In addition, the plastic film on the top of the greenhouse has good light transmittance, which can well transmit sunlight into the grapevine of the greenhouse, which also explains the reason why the indoor and outdoor results are similar.

Our results showed (Figures 3 and 4 ) that the positive correlation between MDS and VPD was extremely significant $(p<0.01)$, and the negative correlation between DI and VPD was significant $(p<0.05)$. Goldhamer et al. [16] indicated that VPD was the main factor affecting the stem diameter variation of almond trees. Moriana et al. [49] showed that $T_{a}$ had the best correlation with MDS, followed by VPD, which was different from the results of this study, and these discrepancies may have been caused by the differences in plant type and test sites. Therefore, when the crop growth environment is changed, the relationship between the indicator of stem diameter and meteorological factors may change, so the reference equation obtained under a specific condition cannot be used to calculate the reference value, which needs to be further referenced with local meteorological data.

In addition, under the same experimental conditions, due to the different responses of different grapevine varieties to water stress, there may be differences in the stomatal resistance, transpiration rate, and photosynthetic rate under different varieties following water deficit, which may cause changes in sap flow in the stem, resulting in differences in the stem diameter indicators of different grapevine varieties [50,51]. Therefore, the reference equation obtained on a certain grapevine variety and the $\mathrm{SI}_{\mathrm{MDS}}$ and $\mathrm{SI}_{\mathrm{DI}}$ irrigation threshold values may no longer be applicable. When calculating the crop reference value, it is better to use the same crop variety under the same growth conditions as the reference crop.

\subsection{Signal Value and Signal-to-Noise Ratio of the Stem Diameter}

The stem diameter indicator is greatly affected by external meteorological factors. The model of the correlations between MDS and DI and stem water potential, RWC and soil moisture cannot exclude the interference of external factors [14]. According to the experimental results, the $\mathrm{SI}_{\mathrm{MDS}}$ and $\mathrm{SI}_{\mathrm{DI}}$ had better sensitivity, signal intensity and reliability in diagnosing the grapevine water content. In addition, the diagnostic applicability of $\mathrm{SI}_{\mathrm{MDS}}$ and $\mathrm{SI}_{\mathrm{DI}}$ was different in different growth stages of grapevine. A possible explanation might be the great coefficient of variation among grapevine plants growth rates masked the differences created by water stress on $\mathrm{SI}_{\mathrm{MDS}}$ at early and middle growth stage. Thus, the $\mathrm{SI}_{\mathrm{DI}}$ is a more appropriate indicator of the grapevine water content than $\mathrm{SI}_{\mathrm{MDS}}$ during the vegetative and flowering stages, but as important plant growth indexes, the variation of SI $\mathrm{MDS}_{\text {and }} \mathrm{SI}_{\mathrm{DI}}$ should be taken into full consideration in practice as well. The signal value of the stem diameter variation indicator can eliminate the interference of meteorological factors, so an accurate reference value is critical for the use of signal intensities for guiding crop irrigation [52,53]. The $\mathrm{SI}_{\mathrm{MDS}}$ and $\mathrm{SI}_{\mathrm{DI}}$ values of the W1 treatment fluctuated up and down by approximately 1 (Figure 6). The $\mathrm{SI}_{\mathrm{MDS}}$ and $\mathrm{SI}_{\mathrm{DI}}$ maximum of the $\mathrm{W} 2$ and $\mathrm{W} 3$ treatments under water stress was approximately 2.0, and the water deficit led to a significant increase in $\mathrm{SI}_{\mathrm{MDS}}$ and $\mathrm{SI}_{\mathrm{DI}}$ compared with the full irrigation treatment. The reason for these findings may be related to the water absorption by the root system and the ability of the stem to transport water following water stress, but the details of these mechanisms should be researched in the future. The $\mathrm{SI}_{\mathrm{DI}}$ at the mature stage showed an irregular curve with large fluctuations, which may have been caused by the large fluctuation of meteorological factors at the mature stage. However, the variation curve of $\mathrm{SI}_{\mathrm{MDS}}$ at the mature stage was relatively stable, which may have been related to 
the stem growth characteristics of grapevine at the later growth stage; the relevant internal physiological mechanism needs to be further explored.

Although stem water potential and RWC measurements require frequent trips to the field and a considerable input of labor, these parameters are reliable plant-based water status indicators and have been used for irrigation scheduling in fruit trees $[43,54-56]$. The present results showed that there were weak correlations between MDS, DI and stem water potential and RWC. These results were due to the unstable meteorological factors during this period, which affected the short-term grapevine stem growth to a certain extent, resulting in the unstable changes in stem diameter. However, when the interference of meteorological factors on MDS and DI were eliminated, $\mathrm{SI}_{\mathrm{MDS}}$ and $\mathrm{SI}_{\mathrm{DI}}$ were not sensitive to meteorological factors. According to the fitting equations of grape stem water potential and RWC with $\mathrm{SI}_{\mathrm{MDS}}$ and $\mathrm{SI}_{\mathrm{DI}}$, the fitting effect of each equation is good (Figure 8). The coefficient of determination $\left(R^{2}\right)$ is approximately 0.7 , which indicates that it is feasible to use the signal intensity of stem diameter variation to characterize crop water status. This approach can not only substantially reduce the labor required but also can be used to continuously and nondestructively carry out index observation, which is consistent with the research results of Badal et al. [17]. Furthermore, when using this index to diagnose the plant water content, the best time is on a fine day, as the stem diameter microchange indexes were small and not significantly different $(p>0.05)$ between stress and full irrigation treatments under poor weather conditions in this experiment [6].

It can be seen from Figures 9 and 10 that the larger coefficient of variation (CV) of $\mathrm{SI}_{\mathrm{MDS}}$ during the vegetative and flowering stages, which resulted in lower signal-to-noise ratio. While $\mathrm{SI}_{\mathrm{DI}}$ has a greater variability in the late growth stage, the larger $\mathrm{CV}$ of $\mathrm{SI}_{\mathrm{MDS}}$ and $\mathrm{SI}_{\mathrm{DI}}$ increased the uncertainty of judging water stress in grapevine. In order to further explore the applicability of $\mathrm{SI}_{\mathrm{MDS}}$ and $\mathrm{SI}_{\mathrm{DI}}$ at different growth stages, more sensors should be installed to acquire the real water content message in practice. Previous studies have shown that some factors could affect the plant CV of MDS such as the crop load, location of sensor installation, and so on $[43,48,49,57]$. The relative researches should be studied further in future experiments to facilitate practical operation of this technic.

\section{Conclusions}

This work shows that there were significant differences in stem diameter variation under different irrigation levels. Water shortage resulted in larger maximum daily shrinkage and smaller daily increase. The stem water potential and leaf relative water content of stress plants (W2 and W3 treatment) were significantly lower than that of the W1 treatment. Regression analysis between MDS, DI and meteorological factors revealed that the MDS of stem diameter was positively correlated with $R_{a}, T_{a}$ and VPD and negatively correlated with $\mathrm{RH}$, and the DI among three treatments decreased with the increase in $\mathrm{R}_{\mathrm{a}}, \mathrm{T}_{\mathrm{a}}$ and VPD and increased with the increase in RH. The key meteorological factors influencing grapevine stem diameter variation in a greenhouse were VPD and $T_{a}$. The MDS and DI had a weak correlation with stem water potential and RWC, thus these measures cannot be directly applied as indicators of the moisture status of grapevine and soil. SI $\mathrm{MDS}_{\mathrm{S}}$ and SI II can distinguish the differences in the grapevine stem diameter indicators under different soil moisture conditions, eliminate the interference of meteorological factors, and were highly correlated with stem water potential, RWC and soil moisture content. At the vegetative and flowering stages, $\mathrm{SI}_{\mathrm{DI}}$ has less variability and greater reliability than $\mathrm{SI}_{\mathrm{MDS}}$, it is more suitable for the diagnosis of grapevine water status in these two periods. At the fruit expansion and the mature stages, the signal-to-noise ratio of $\mathrm{SI}_{\mathrm{MDS}}$ is significantly higher than that of $\mathrm{SI}_{\mathrm{MDS}}$, so it is more suitable to be used as a diagnostic index of water status in late growth stage of grapevine. In sum, compared with other plant water diagnosing indexes, the SIMDS and SIDI indexes had the advantages of sensitivity, signal intensity and reliability and were good indicators of the grapevine water content. 
Author Contributions: C.R., X.H., W.W. and H.R. designed the experiments, C.R., Y.G. and T.S. performed research and date analysis, C.R. wrote the manuscript with contributions from all authors. All authors have read and agreed to the published version of the manuscript.

Funding: This work was supported by the National Key Research and Development Program of China (2017YFD0201508), the National Natural Science Foundation of China (51179163), Shaanxi Key Science and Technology Innovation Team Project (2016KTZDNY-01-05).

Institutional Review Board Statement: Not applicable.

Informed Consent Statement: Not applicable.

Data Availability Statement: Data is available upon request to the corresponding author.

Acknowledgments: The authors would like to acknowledge all the team members of key Laboratory of Agricultural Soil and Water Engineering in Arid and Semiarid Areas, Ministry of Education.

Conflicts of Interest: The authors declare that they have no conflict of interest.

\section{References}

1. Goodwin, I.; Boland, A.M. Scheduling deficit irrigation of fruit trees for optimizing water use efficiency. In Deficit Irrigation Practices, Water Reports; FAO: Quebec City, QC, Canada, 2002; Volume 22, p. 109.

2. Naor, A.; Gal, Y.; Peres, M. The inherent variability of water stress indicators in apple, nectarine and pear orchards, and the validity of a leaf-selection procedure for water potential measurements. Irrig. Sci. 2005, 24, 129-135. [CrossRef]

3. Jones, H.G. Irrigation scheduling: Advantages and pitfalls of plant-based methods. J. Exp. Bot. 2004, 407, 2427. [CrossRef]

4. Fernández, J.E.; Cuevas, M.V. Irrigation scheduling from stem diameter variations: A review. Agric. For. Meteorol. 2010, 150, 135-151. [CrossRef]

5. Argyrokastritis, I.G.; Papastylianou, P.T.; Alexandris, S. Leaf Water Potential and Crop Water Stress Index variation for full and deficit irrigated cotton in Mediterranean conditions. Agric. Agric. Sci. Procedia 2015, 4, 463-470. [CrossRef]

6. Wang, X.; Meng, Z.; Chang, X.; Deng, Z.; Li, Y.; Lv, M. Determination of a suitable indicator of tomato water content based on stem diameter variation. Sci. Hortic. 2017, 215, 142-148. [CrossRef]

7. Ojeda, H.; Deloire, A.; Carbonneau, A. Influence of water deficits on grape berry growth. Vitis 2001, 40, 141-145. [CrossRef]

8. González-Fernández, A.B.; Rodríguez-Pérez, J.R.; Marcelo, V.; Valenciano, J.B. Using field spectrometry and a plant probe accessory to determine leaf water content in commercial vineyards. Agric. Water Manag. 2015, 156, 43-50. [CrossRef]

9. Gao, Y.; Qiu, J.W.; Miao, Y.L.; Qiu, R.C.; Li, H.; Zhang, M. Prediction of Leaf Water Content in Maize Seedlings Based on Hyperspectral Information. IFAC-Pap. 2019, 52, 263-269. [CrossRef]

10. Li, B.; Zhao, X.T.; Zhang, Y.; Zhang, S.J.; Luo, B. Prediction and monitoring of leaf water content in soybean plants using terahertz time-domain spectroscopy. Comput. Electron. Agric. 2020, 170, 105239. [CrossRef]

11. Jiménez, M.N.; Navarro, F.B.; Sánchez-Miranda, A.; Ripoll, M.A. Using stem diameter variations to detect and quantify growth and relationships with climatic variables on a gradient of thinned Aleppo pines. For. Ecol. Manag. 2019, 442, 53-62. [CrossRef]

12. Ortuño, M.F.; García-Orellana, Y.; Conejero, W.; Ruiz-Sanchez, M.C.; Mounzer, O.; Alarcon, J.J.; Torrecillas, A. Relationships Between Climatic Variables and Sap Flow, Stem Water Potential and Maximum Daily Trunk Shrinkage in Lemon Trees. Plant Soil 2006, 279, 229-242. [CrossRef]

13. Leperen, W.V.; Volkov, V.S.; Meeteren, U.V. Distribution of xylem hydraulic resistance in fruiting truss of tomato influenced by water stress. J. Exp. Bot. 2003, 54, 317-324. [CrossRef]

14. Ortuño, M.F.; Conejero, W.; Moreno, F.; Moriana, A.; Intrigliolo, D.S.; Biel, C.; Mellisho, C.D.; Pérez-Pastor, A.; Domingo, R.; Ruiz-Sánchez, M.C.; et al. Could trunk diameter sensors be used in woody crops for irrigation scheduling? A review of current knowledge and future perspectives. Agric. Water Manag. 2010, 97, 1-11. [CrossRef]

15. Schepper, V.D.; Dusschoten, D.V.; Copini, P.; Jahnke, S.; Steppe, K. MRI links stem water content to stem diameter variations in transpiring trees. J. Exp. Bot. 2012, 63, 2645-2653. [CrossRef]

16. Goldhamer, D.A.; Fereres, E. Irrigation scheduling of almond trees with trunk diameter sensors. Irrig. Sci. 2004, 23, 11-19. [CrossRef]

17. Badal, E.; Buesa, I.; Guerra, D.; Bonet, L.; Ferrer, P.; Intrigliolo, D.S. Maximum diurnal trunk shrinkage is a sensitive indicator of plant water, stress in Diospyros kaki (Persimmon) trees. Agric. Water Manag. 2010, 98, 143-147. [CrossRef]

18. Doltra, J.; Oncins, J.A.; Bonany, J.; Cohen, M. Evaluation of plant-based water status indicators in mature apple trees under field conditions. Irrig. Sci. 2007, 25, 351-359. [CrossRef]

19. Velez, J.E.; Intrigliolo, D.S.; Castel, J.R. Scheduling deficit irrigation of citrus trees with maximum daily trunk shrinkage. Agric. Water Manag. 2007, 90, 197-204. [CrossRef]

20. Moriana, A.; Fereres, E. Plant indicators for scheduling irrigation of young olive trees. Irrig. Sci. 2002, 21, 83-90. [CrossRef]

21. Fereres, E.; Goldhamer, D.A. Suitability of stem diameter vriations and water potential as indicators for irrigation scheduling of almond trees. J. Hortic. Sci. Biotechnol. 2003, 78, 139-144. [CrossRef] 
22. Intrigliolo, D.S.; Castel, J.R. Continuous measurement of plant and soil water status for irrigation scheduling in plum. Irrig. Sci. 2004, 23, 93-102. [CrossRef]

23. Ortuño, M.F.; García-Orellana, Y.; Conejero, W.; Pérez-Sarmiento, F.; Torrecillas, A. Assessment of maximum daily trunk shrinkage signal intensity threshold values for deficit irrigation in lemon trees. Agric. Water Manag. 2008, 96, 80-86. [CrossRef]

24. Katerji, N.; Itier, B.; Ferreira, I. Etude de quelques criteres indicateurs de l'etat hydrique d'une culture de tomate en region semi-aride. Agronomie 1988, 8, 425-433. [CrossRef]

25. Rötzer, T.; Biber, P.; Moser, A.; Schäfer, C.; Pretzsch, H. Stem and root diameter growth of European beech and Norway spruce under extreme drought. For. Ecol. Manag. 2017, 406, 184-195. [CrossRef]

26. Matimati, I.; Musil, C.F.; Raitt, L.; February, E.C. Diurnal stem diameter variations show CAM and C3 photosynthetic modes and CAM-C3 switches in arid South African succulent shrubs. Agric. For. Meteorol. 2012, 161, 72-79. [CrossRef]

27. Tognetti, R.; Giovannelli, A.; Lavini, A.; Morelli, G.; Fragnito, F.; d'Andria, R. Assessing environmental controls over conductances through the soil-plant-atmosphere continuum in an experimental olive tree plantation of southern Italy. Agric. For. Meteorol. 2009, 149, 1229-1243. [CrossRef]

28. Devine, W.D.; Harrington, C.A. Factors affecting diurnal stem contraction in young Douglas-fir. Agric. For. Meteorol. 2011, 151, 414-419. [CrossRef]

29. Du, S.Q.; Tong, L.; Zhang, X.T.; Kang, S.Z.; Du, T.S.; Li, S.; Ding, R.S. Signal intensity based on maximum daily stem shrinkage can reflect the water status of apple trees under alternate partial root-zone irrigation. Agric. Water Manag. 2017, 190, 21-30. [CrossRef]

30. Tuccio, L.; Piccolo, E.L.; Battelli, R.; Matteoli, S.; Remorini, D. Physiological indicators to assess water status in potted grapevine (Vitis vinifera L.). Sci. Hortic. 2019, 255, 8-13. [CrossRef]

31. Conesa, M.R.; Torres, R.; Domingo, R.; Navarro, H.; Soto, F.; Pérez-Pastor, A. Maximum daily trunk shrinkage and stem water potential reference equations for irrigation scheduling in table grapes. Agric. Water Manag. 2016, 172, 51-61. [CrossRef]

32. Gallardo, M.; Thompson, R.B.; Valdez, L.C.; Fernandez, M.D. Use of stem diameter variations to detect plant water stress in tomato. Irrig. Sci. 2006, 24, 241-255. [CrossRef]

33. Goldhamer, D.A.; Fereres, E. Irrigation scheduling protocols using continuously recorded trunk diameter measurements. Irrig. Sci. 2001, 20, 115-125. [CrossRef]

34. Miralles, J.; Franco, J.A.; Sánchez-Blanco, M.J.; Bañón, S. Effects of pot-in-pot production system on water consumption 0034, stem diameter variations and photochemical efficiency of spindle tree irrigated with saline water. Agric. Water Manag. 2016, 170, 167-175. [CrossRef]

35. Allen, R.G. Using the FAO-56 dual crop coefficient method over an irrigated region as part of an evapotranspiration intercomparison study. J. Hydrol. 2000, 229, 27-41. [CrossRef]

36. Abdelfatah, A.; Aranda, X.; Savé, R.; Herralde, F.D.; Biel, C. Evaluation of the response of maximum daily shrinkage in young cherry trees submitted to water stress cycles in a greenhouse. Agric. Water Manag. 2013, 118, 150-158. [CrossRef]

37. Kramer, P.J. Water Relations of Plants; Academic Press: New York, NY, USA, 1983.

38. Turner, N.C. Techniques and experimental approaches for the measurement of plant water status. Plant Soil 1981, 58, 339-366. [CrossRef]

39. Zhang, J.G.; He, Q.Y.; Shi, W.Y.; Otsuki, K.; Yamanaka, N.; Du, S. Radial variations in xylem sap flow and their effect on whole-tree water use estimates. Hydrol. Process. 2015, 29, 4993-5002. [CrossRef]

40. Irvine, J.; Grace, J. Continuous measurements of water tensions in the xylem of trees based on the elastic properties of wood. Planta 1997, 202, 455-461. [CrossRef]

41. Xiong, W.; Wang, Y.H.; Yu, P.T.; Liu, H.L.; Shi, Z.J.; Guan, W. Growth in stem diameter of Larix principis-rupprechtii and its response to meteorological factors in the south of Liupan Mountain, China. Acta Ecol. Sin. 2007, 27, 432-440. [CrossRef]

42. Zhang, J.Y.; Duan, A.W.; Meng, Z.J.; Liu, Z.G. Stem diameter variations of cotton under different water conditions. Trans. Chin. Soc. Agric. Eng. 2005, 21, 7-11.

43. Intrigliolo, D.S.; Castel, J.R. Evaluation of grapevine water status from trunk diameter variations. Irrig. Sci. 2007, 26, 49-59. [CrossRef]

44. Girón, I.F.; Corell, M.; Martín-Palomo, M.J.; Galindo, A.; Torrecillas, A.; Moreno, F.; Moriana, A. Feasibility of trunk diameter fluctuations in the scheduling of regulated deficit irrigation for table olive trees without reference trees. Agric. Water Manag. 2015, 161, 114-126. [CrossRef]

45. De la Rosa, J.M.; Conesa, M.R.; Domingo, R.; Torres, R.; Pérez-Pastor, A. Feasibility of using trunk diameter fluctuation and stem water potential reference lines for irrigation scheduling of early nectarine trees. Agric. Water Manag. 2013, 126, 133-141. [CrossRef]

46. Kanai, S.; Adu-Gymfi, J.; Lei, K.; Lto, J.; Ohkura, K.; Moghaieb, R.E.A.; El-shemy, H.; Mohapatra, R.; Mohapatra, P.K.; Saneoka, H.; et al. N-deficiency damps out circadian rhythmic changes of stem diameter dynamics in tomato plant. Plant Sci. 2008, 174, 183-191. [CrossRef]

47. Swaef, T.D.; Steppe, K.; Lemeur, R. Raoul Lemeur. Determining reference values for stem water potential and maximum daily trunk shrinkage in young apple trees based on plant responses to water deficit. Agric. Water Manag. 2009, 96, 541-550. [CrossRef]

48. Conejero, W.; Mellisho, C.D.; Ortuo, M.F.; Moriana, A.; Moreno, F.; Torrecillas, A. Using trunk diameter sensors for regulated deficit irrigation scheduling in early maturing peach trees-ScienceDirect. Environ. Exp. Bot. 2011, 71, 409-415. [CrossRef] 
49. Moriana, A.; Moreno, F.; Girón, I.F.; Conejero, W.; Ortuño, M.F.; Morales, D.; Corell, M.; Torrecillas, A. Seasonal changes of maximum daily shrinkage reference equations for irrigation scheduling in olive trees: Influence of fruit load. Agric. Water Manag. 2011, 99, 121-127. [CrossRef]

50. King, G.; Fonti, P.; Nievergelt, D.; Büntgen, U.; Frank, D. Climatic drivers of hourly to yearly tree radius variations along a $6{ }^{\circ} \mathrm{C}$ natural warming gradient. Agric. For. Meteorol. 2013, 168, 36-46. [CrossRef]

51. Janbek, B.M.; Stockie, J.M. Asymptotic and numerical analysis of a porous medium model for transpiration-driven sap flow in trees. Siam J. Appl. Math. 2017, 78, 2028-2056. [CrossRef]

52. De la Rosa, J.M.; Conesa, M.R.; Domingo, R.; Pérez-Pastor, A. A new approach to ascertain the sensitivity to water stress of different plant water indicators in extra-early nectarine trees. Sci. Hortic. 2014, 169, 147-153. [CrossRef]

53. De la Rosa, J.M.; Domingo, R.; Gómez-Montiel, J.; Pérez-Pastor, A. Implementing deficit irrigation scheduling through plant water stress indicators in early nectarine trees. Agric. Water Manag. 2015, 152, 207-216. [CrossRef]

54. Shackel, K.A.; Ahmadi, H.; Biasi, W.; Buchner, R.; Goldhamer, D.; Gurusinghe, S.; Hasey, J.; Kester, D.; Krueger, B.; Lampinen, B.; et al. Plant water status as an index of irrigation need in deciduous fruit trees. HortTechnology 1997, 7, 23-29. [CrossRef]

55. Naor, A. Midday stem water potential as a plant water stress indicator for irrigation scheduling in fruit trees. Acta Hortic. 2000, 537, 447-454. [CrossRef]

56. Choné, X.; Cornelis, V.L.; Denis, D.; Gaudillère, J.P. Stem Water Potential is a Sensitive Indicator of Grapevine Water Status. Ann. Bot. 2001, 4, 477-483. [CrossRef]

57. Cuevas, M.V.; Torres-Ruiz, J.M.; Álvarez, R.; Jiménez, M.D.; Cuerva, J.; Fernández, J.E. Assessment of trunk diameter variation derived indices as water stress indicators in mature olive trees. Agric. Water Manag. 2010, 97, 1293-1302. [CrossRef] 